\title{
The WELSONS experiment: overview and presentation of first results on the surface atmospheric boundary-layer in semiarid Spain
}

\author{
J.-P. Frangi, D. C. Richard \\ Laboratoire Environnement et Développement, CP 7071, Université Paris 7 - Denis Diderot 2 pl. Jussieu 75251 Paris, France \\ E-mail: frangi@ccr.jussieu.fr
}

Received: 25 February 1999 / Revised: 2 November 1999 / Accepted: 5 November 1999

\begin{abstract}
This study presents the preliminary results of the local energy budget and dynamic characteristics of the surface atmospheric boundary-layer (SBL) during the WELSONS (wind erosion and losses of soil nutrients in semiarid Spain) experiment. Some Mediterranean regions suffer land degradation by wind erosion as a consequence of their particular soil and climate conditions and inappropriate agricultural practice. In Spain, where land degradation by water erosion is well known, the lack of field studies to quantify soils losses by wind erosion resulted in the European Community organizing a scientific program for this specific issue. The European programme known as WELSONS was devoted to study the wind erosion process in central Aragon (NE Spain). This multidisciplinary experiment, which began in 1996 and finished in 1998, was carried out over an agricultural soil which was left fallow. Within the experimental field, two plots were delimited where two tillage treatments were applied, a mould-board ploughing (or conventional tillage denoted CT) and chisel ploughing (reduced tillage denoted RT). This was to study on bare soil the influence of tillage method on surface conditions, saltation flux, vertical dust flux, erosion rates, dynamics characteristics such as friction velocity, roughness length, etc., and energy budget. The partitioning of the available energy, resulting from the dynamics of the SBL, are quite different over the two plots because of their own peculiar soil and surface properties. The first results show that the RT treatment seems to provide a wind erosion protection. Because of the long data recording time and particular phenomena (formation of a crust at the soil surface, very dry conditions, high wind speed for instance), these microclimatological data acquired during the WELSONS programmes may be helpful to test atmospheric boundary-layer models coupled with soil models.
\end{abstract}

Key words: Hydrology (desertification) Meterology and atmospheric dynamics (general)

Correspondence to: J.-P. Frangi

\section{Introduction}

Soil erosion is a major environmental and agricultural issue that has worsened during recent decades. Soil erosion rates in the United States and Europe average 10 tons ha ${ }^{-1}$ year $^{-1}$ by wind (Barrow, 1991). Because of their particular climate, the arid and semiarid regions, where wind erosion frequently is dominant over water erosion, are clearly the main sources of atmospheric soil dust transported over great distances. The production of dust is closely connected to major changes in climate. For instance, it has been suggested that the concentration of aeolian components which constitute a major part of the sediment found both on the continents and in the oceans, would rise with increasing aridity in the source area (e.g. De Angelis et al., 1987; Rea et al., 1985). The short-term meteorological and climatic variations, such as those resulting from anthropogenic activities, are likely to increase the aridity and, consequently, to extend the frequency and intensity of soil deflation events (Prospero and Nees, 1986). In agricultural environments, wind erosion can even be aggravated by human activity and/or land-use changes, including those driven by climate. It has been acknowledged that land-use changes and degradations due to economic, social or political pressures are probably greater than those brought about by climate alone. The effects of climate may be at least as critical as anthropogenic effects in agricultural semiarid regions only.

Wind erosion is also an important process in geology, especially in the formation of soils and deep sea sediments. On the continents, the millenary sedimentation of windblown dust is responsible for loess formation where the vegetation plays a crucial role in trapping dust. However, there is no accumulation of dust where, for instance plant cover was erased by aridity, since these areas are eroded again by wind. For semiarid Canadian prairies, Larney et al. (1995) conclude that, assuming the fastest renewal rates reported for the A horizon material ( $25.4 \mathrm{~mm}$ per 30 years), it would take 
about 17 years of natural soil formation to regain the topsoil (the first centimetres of soil particles from the soil surface) lost during this study (14.4 $\mathrm{mm}$ of topsoil removed between April 1991 and May 1992). Wind erosion represents a long-term soil loss. This process is selective, removing the finest particles that contain disproportionately greater amounts of plant nutrients, the reduction of storage capacity for plant-available water, and the degradation of soil structure. However, nutrient losses have the greatest effect on the reduction of crop productivity over a short-term period as well.

Losses of soil nutrients in Europe due to water erosion are well documented, with many experiences during the 1980s, the latest being the great project on the Mediterranean Desertification and Land Use (MEDALUS), described in Kosmas et al. (1997). On the other hand, only few data are available on the loss of nutrients due to wind erosion on agricultural lands in Europe, and thus, despite the concern expressed, about its environmental and economic impact too (Eppink and Spaan, 1989; Frielinghaus, 1991). A few experiments were performed in Europe in the past to study wind erosion but they only concerned northern and central Europe (Moller, 1986; Richter, 1980; Stebelski, 1985). This lack of information stimulated the European Community to carry out a research policy concerning the specific issue of Mediterranean agricultural soils. Arable lands in the semiarid European Mediterranean region are particularly prone to wind erosion because of aridity and soil moisture deficit, irregular but intensive precipitation, weak soil structure and limited vegetation cover (Conacher et al., 1998).

WELSONS (wind erosion and losses of soil nutrients in semiarid Spain) is a European research project devoted to study desertification and land degradation by wind erosion in the European Mediterranean area. In the "Soil Erosion Map of Western Europe" (De Ploey et al., 1989), the central Aragon region (northern Spain) is mentioned as one of the potential wind erosion areas in Europe. This area is one of the driest in the Iberian peninsula and also one of the most semiarid areas in western Europe. Its unique climatic and lithological characteristics make this area possibly subject to land degradation by desertification process. Recent studies show this region is extremely sensitive to erosion by water (e.g. Sala et al., 1991), but studies on wind erosion are very scarce (Quirantes, 1989), and so far no attempt has been made to assess soil degradation due to wind erosion. A preliminary study on dust emissions in this area was set up for a short period in 1995 (Lopez et al., 1998). This first experiment showed the need to monitor the wind erosion processes and their relationship with agricultural practices (tillage effects) more precisely. Factors affecting windblown dust in central Aragon can be grouped into three categories: soil type, land use and management, and climate.

The main objective of the WELSONS project is to provide a better understanding of the impacts of climate and land-use changes on soil degradation by wind erosion for agricultural soils in semiarid region of the northern Spain. This can be done over a short-term or a long-term period, first, by investigating the removal of nutrient-rich soil particles due to wind erosion, and then by developing a soil nutrient emission model expressed in terms of parameters which are likely to be modified by those changes. The scientific partners involved in WELSONS are complementary experts in soil, soil erosion, aerosols and micrometeorology, as mentioned in Table 1.

The aim of our work as (partner 5 in Table 1) in the WELSONS project is to analyze the physical processes within the soil/atmosphere interface in order to quantify the transfer of energy, momentum and matter between the soil and the atmosphere. Wind erosion occurs only
Table 1. Scientific partners and goals in the WELSONS project. The WELSONS experiments were performed by five different institutions, experts in atmospheric dust and airborne particle characterization, soil science, saltation and horizontal flux, and micrometeorology, making for a total study of the wind erosion process

\begin{tabular}{|c|c|c|c|}
\hline Organization & Measured quantities & Instrument type & Purpose \\
\hline $\begin{array}{l}\text { Consejo Superior de } \\
\text { Investigaciones Cientificas- } \\
\text { Estacion Experimental de } \\
\text { Aula Dei (CSIC-EEAD, } \\
\text { Zaragoza, Spain) }\end{array}$ & $\begin{array}{l}\text { Particle size distribution, } \% \text { of } \\
\text { aggregate, } \mathrm{EC}, \mathrm{pH} \text {, organic } \\
\text { mater and } \mathrm{CaCO}_{3} \text { content, } \\
\text { humidity, density, roughness... }\end{array}$ & $\begin{array}{l}\text { Light-scattering particle size } \\
\text { analyser, pHmeter }\left(\mathrm{H}_{2} \mathrm{O} / \mathrm{KCl}\right) \\
\text { penetrometer; electromagnetic } \\
\text { sieve shaker... }\end{array}$ & $\begin{array}{l}\text { Soil surface properties; } \\
\text { collection of soil and } \\
\text { climate data relevant to } \\
\text { the project }\end{array}$ \\
\hline $\begin{array}{l}\text { Wageningen Agricultural } \\
\text { University (WAU, } \\
\text { Wageningen, The } \\
\text { Netherlands) }\end{array}$ & $\begin{array}{l}\text { Vertical profile of saltation } \\
\text { particles; horizontal transport } \\
\text { in saltation mode }\end{array}$ & $\begin{array}{l}\text { Modified Wilson and Cooke } \\
\text { (MWAC) catchers; saltiphones }\end{array}$ & Threshold friction velocity \\
\hline $\begin{array}{l}\text { Fraunhofer Institut für } \\
\text { Toxikologie and Aerosolfor- } \\
\text { schung (PhITA, Hannover, } \\
\text { Germany) }\end{array}$ & $\begin{array}{l}\text { Airborne particle size } \\
\text { characterization }\end{array}$ & $\begin{array}{l}\text { Standard soil resuspension } \\
\text { test (SSRT) }\end{array}$ & $\begin{array}{l}\text { Determination of the soil } \\
\text { erodibility }\end{array}$ \\
\hline
\end{tabular}


when a threshold value of the wind velocity is reached. This threshold depends on the soil surface features and the characteristics of the flow just above the soil surface, this flow being itself influenced by the soil surface. The mechanical energy of the wind is transferred to the soil particles by the shear stress at the surface. The latter is directly linked to the friction velocity and surface conditions. The threshold friction velocity is mainly influenced by the roughness of the surface which acts to absorb a part of momentum of the wind, the particle size distribution at the surface (e.g. Chepil, 1951), and the humidity of the soil. Using theoretical considerations, it is possible to parameterize the surface and atmospheric properties influencing wind erosion process, namely by using a limited number of parameters which interact: friction velocity, roughness length, latent heat flux, retention curve and matrix potential of the soil, soil particle distribution, vegetation cover, etc. Micrometeorological parameters, such as the friction velocity (and the threshold friction velocity), the roughness length and evaporation, are very useful parameters to quantify wind erosion (e.g. Fryrear et al., 1993; Gillette et al., 1974; Marticorena and Bergametti, 1997; Quiroga et al., 1998; Zobeck, 1991). Among them, friction velocity is one of the most important since it quantifies the energy source of that moves soil material. The roughness length has a significant effect on the evaporation rate, the solar radiation reflection, the soil particle emission and trapping during a wind erosion event (e.g. Armbrust et al., 1964; Bowers et al., 1965). Evaporation plays a role in inter-particle capillary forces (characterized by the soil moisture) which are the main factors responsible for the increase of the wind erosion threshold (e.g. Bisal et al., 1966; Chepil, 1956; Marticorena et al., 1997). The friction velocity and the roughness length allow us to describe the wind profile, and ultimately to predict wind erosion. As a consequence, from a micrometeorological point of view, understanding the wind erosion processes requires acquaintance with dynamic parameters and the establishment of the radiation balance at the surface.

Many studies of the SBL have taken place during the last decade, but only a large scale and for representative selected climates: HAPEX-MOBILHY in southwest France (André et al., 1986), EFEDA in arid and semiarid Spain (Bolle et al., 1993) and HAPEX-Sahel in the semiarid tropics (Goutorbe et al., 1994), FIFE in central USA (Sellers et al., 1988) and BOREAS in Canada (Sellers et al., 1995). These experiments studied the land-atmosphere interaction in order to improve the parametrization of land surface atmosphere relations (at the global circulation model gridbox scale) and hydrological processes. The ECLATS experiment (Druilhet and Tinga, 1982) studied mainly the interaction between energy budget, aerosols and turbulent transfers in the boundary-layer in the Sahel region. All these studies showed that the energy budget strongly depends on environmental factors, which allows a better understanding of the microclimate. Therefore the WELSONS project has established original local microclimatological data on the semiarid surface layer of the northern Spain.
This study is organized in the following manner: general characteristics of the WELSONS experiment are given in Sect. 2, along with a brief description of the experimental site. In Sect. 3, the methodology is applied and results are presented, the latter being subdivided into time series presentation and dynamics of the SBL; conclusions are provided in Sect. 4.

\section{The WELSONS experiment}

\subsection{Description of the experimental site}

In central Aragon, soils can be defined as mostly alkaline, with low organic matter content $(<1.5 \%)$, high total carbonate content ( $>30 \%$ in many case), and have a dominant sandy loam to loam textural class (Montanes et al., 1991). Due to these characteristics, soils in this region are inclined to erosion both by water and wind. As a first approximation, and applying the empirical index proposed by Lee et al. (1994) for the average clay content of these soils $(17.6 \%)$, the soil erodibility for wind lies in a class intermediate to those found in other semiarid regions (e.g. southern High Plains, USA).

The soil moisture regime in the central part of the Ebro River basin is markedly arid. The distribution of aridisols in Spain according to Dregne (1976) shows these soils are present in much of the Ebro Valley. According to official 1993 statistics (Gobierno de Aragon, 1994), land use distribution in Aragon $\left(47668 \mathrm{~km}^{2}\right)$ is reported as follows: agricultural lands $(37.2 \%)$, rangelands $(14.5 \%)$, forests $(30.8 \%)$ and other uses including marginal lands $(17.5 \%)$. About $75 \%$ of total dry-farmed croplands (1 357283 ha) are semiarid areas with an average annual precipitation of $500 \mathrm{~mm}$ or less, with herbaceous crops cultivated on approximately 750000 ha and 430000 ha of fallow lands. Almost half of fallow lands are concentrated in central Aragon where the traditional farming system of cereal-follow rotation extends over 250000 ha. Lopez et al. (1996) describe the sequence of this rotation in which soil lies fallow for about 16 months. Wind erosion is generally more important on these agricultural lands since the vegetation cover is removed seasonally and soil surface horizons are disturbed by tillage. Attention should be paid to less known processes such as tillage erosion (Gomes et al., 1997) to assess the impact of land use changes on erosion rates. Without measures to maintain clods and lumps of soil and crop residues on the surface, the soil during the fallow period is smooth and bare. This potentially erosive condition extends until the newly seeded crop has grown to protect the soil surface from wind erosive forces again.

The rainfall regime in central Aragon is characterized by the lack of any well-defined rainy season, and a high probability of months where no rain falls or amounts are extremely low (McAneney and Arrue, 1993). This is in contrast to many other semiarid regions with a clear Mediterranean-type climate, such as those in the southeastern part of the country. The climate of this region is 
strongly influenced by the winds because of their particular characteristics. These winds are due to the specific topography of this part of Spain, as can be seen from Fig. 1. In fact, the channel formed by the Cantabrico Cordillera to the northwest, the Pyrénées Mountains to the north and the Iberian Cordillera to the south of the Ebro River, funnels each air flow, resulting in the main wind directions of WNW and ESE. The Cierzo is the wind from the WNW direction, a very cold air stream in winter and cool in summer. Two main meteorological situations can explain its appearance. The first is an anticyclone over the Cantabrico Sea and a low-pressure system above the Mediterranean Sea; the second is a strong low-pressure system to the north of Europe coupled with a high-pressure area over the Azores. The first situation generates dry (from the foehn effect, see Schneider, 1996), strong and continuous winds. Cierzo events with gusts over $30 \mathrm{~m} \mathrm{~s}^{-1}$ are common in this region, especially during the summer (Biel and Garcia de Pedraza, 1962), and according to Skidmore (1965), erosive winds are those exceeding $5.3 \mathrm{~m} \mathrm{~s}^{-1}$ at $2 \mathrm{~m}$ height. In the second case, the air flow which blows over the whole Europe has strong oceanic characteristics and causes wet weather with heavy swell conditions on the Atlantic coastline. In the opposite direction blows the Bochorno, with an ESE main direction, which appears when a pressure gradient exists between Mediterranean Sea and the Cantabrico Sea, with a low pressure field over the latter. The Bochorno is generally a light wind (except in stormy conditions), and its direction is less well-defined; it is temperate and moist in winter, and dry in summer with a Saharan influence.

The experimental field is located in an area called $\mathrm{El}$ Saso $\left(41^{\circ} 36^{\prime} \mathrm{N}, 0^{\circ} 32^{\prime} \mathrm{W}, 285 \mathrm{~m}\right.$ above mean sea level) between Osera de Ebro and Monegrillo, $40 \mathrm{~km}$ apart from Zaragoza in the Ebro Valley (see Fig. 1). At the experiment time the field was in the fallow year of a barley fallow rotation, with its largest dimension in the direction of the prevailing wind, Cierzo (WNW). It was surrounded by fields with very sparse vegetation on the upwind edge. Beyond both sides were wheat fields with a vegetation height $<30 \mathrm{~cm}$ at a distance of about $200 \mathrm{~m}$; fallow stubble fields filled area between wheat fields and the experimental plot. The soil was a silt loam, containing $19.3 \%$ of sand, $67.6 \%$ of silt and $13.1 \%$ of clay in the first $20 \mathrm{~cm}$ from the surface.

Within the experimental field, two adjacent plots were delimited for the application of two tillage treatments with a $20 \mathrm{~m}$ separation: conventional tillage (CT) and reduced tillage (RT). The dimensions of one plot were 130 by $160 \mathrm{~m}$. The CT treatment consisted of mould-board ploughing, to a depth of $30-35 \mathrm{~cm}$, then a compacting roller was used to obtain a very flat surface. The RT treatment is an alternative practice of conservation tillage, and consisted of a single pass of a chisel plough to a depth of about $15-20 \mathrm{~cm}$, resulting in a

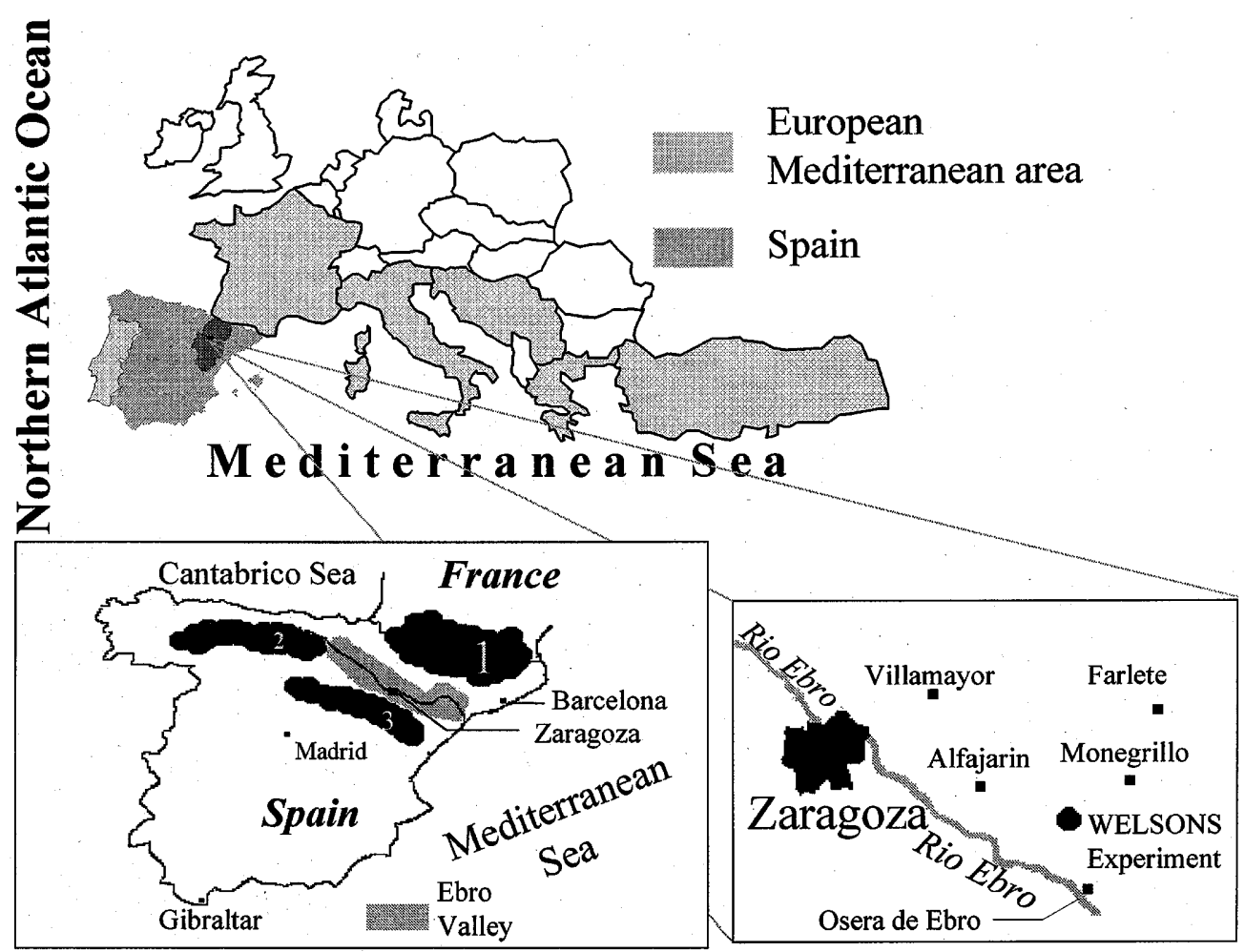

Fig. 1. Map of the area studied. Top shows the Aragon region in dark grey within Spain. The WELSONS experiment site is situated between Osera de Ebro and Monegrillo, at about $40 \mathrm{~km}$ from Zaragoza in the Ebro Valley. The bottom-right map allows us to visualize the specific geography of this region, with the Pyrénées Mountains (1) which separates Spain from France, the Cantabrico Cordillera (2) in northern Spain and the (3) Iberico Cordillera to the south of the Ebro Valley. This geographical configuration causes special effects on winds blowing through this region, and influences the climate regime in this part of northern Spain 
surface with furrows. In both cases, all the tillage operations were done in the WNW direction. Thus the fields were in a bare soil state, but with surface conditions that were very different during the whole experiment. This work only presents the 1997 WELSONS experiment (29 June-25 September) which was the most intensive and over the longest measurement period. Data have been recorded over the two different plots, and Table 2 gives the different periods in the 1997 WELSONS experiment.

\subsection{Instrumentation and measurements}

Two micrometeorological ground stations (MGS) have been developed and set up on the experimental field (see Fig. 2) with one on each of the plots and close to the dust flux tower (LISA) on the downwind edge of the field to avoid a fetch effect. The MGS is an instrument that combines sensing and computing functions in a single package to make continuous measurements of micrometeorological parameters. This kind of equipment has already been used in agrometeorological applications (Frangi et al., 1996) such as irrigation management, and has been adapted for the WELSONS experiment. It records the radiative and thermodynamic measurements (FT data) and also wind speed at five levels during wind erosion events (WS data). The wind profile is measured independently of the energy budget parameters (radiative and thermodynamic measurements as wind speed, wind direction, air temperature and vapour pressure, net radiation flux, ground heat flux, soil and surface temperature, atmospheric pressure) which are not affected and the MGS continue to measure them every $3 \mathrm{~min}$ (Frangi and Poullain, 1997). Each wind speed file has an energy budget file to correlate energetic and aerodynamics data (both form the WS database). Moreover, it has been possible to ensure wind profiles that were common in time to the two stations, and this enabled us to compare dynamic characteristics of the two parcels, which have different tillage modes.

Statistical errors for each sensor are presented in Table 3, where the error on wind speed concerns the anemometer coupled with vanes. Other anemometers involved on the wind profile determination were cali-

Table 2. The rain coupled with the high net radiation flux and specific soil texture results in a crust on the soil surface. We had to remove it twice during the 1997 WELSONS experiment (15 July and 3 September) by new tillage operations, and consequently this experiment has been divided into three periods. These repeated tillage processes allowed us to record enough data to characterize erosion processes and micrometeorological features. These periods must be distinguished because after a tillage operation, the soil structure is different, such as roughness length and soil properties

\begin{tabular}{ll}
\hline Experiment & Start-end date (total number of days) \\
\hline Phase I & 19 June-5 July (26) \\
Phase II & 16 July-3 September (49) \\
Phase III & 4 September-25 September (21) \\
\hline
\end{tabular}

brated in a wind tunnel, with a final error on each of about $0.1 \mathrm{~m} \mathrm{~s}^{-1}$. The inversion process involves a time difference between the measurement of the air temperature (as much for humidity) at the low level and the measurement at the upper level. That implies an error on the estimation of the temperature and humidity gradients because natural conditions may have changed

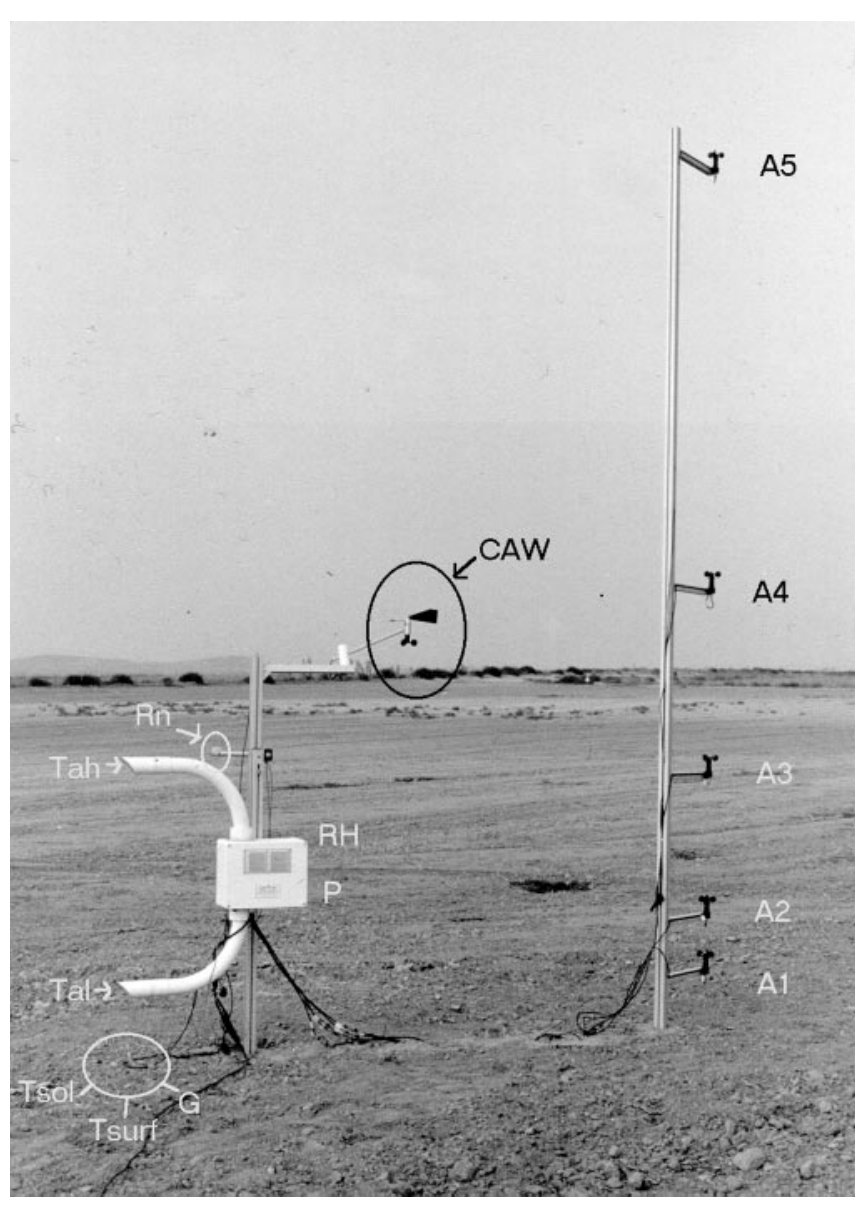

Fig. 2. Two micrometeorological ground stations (MGS) were set up during the WELSONS experiment. The wind profile, recorded every second, is measured with 5 cup anemometers marked $A 1, A 2, A 3, A 4$ and $A 5$ along a vertical mast $4 \mathrm{~m}$ in height (right side of picture), near the station which is a datalogger with sensing and computing functions. Other measured parameters, radiative and thermodynamic data for the determination of the energy budget, are the following (3 min-measurements and 30 min-means): wind speed and direction by a cup anemometer and wind wane marked $C A W$ on the figure; the net radiation flux sensor is $R n$; Tsol, Tsurf and $G$ are respectively the soil temperature probe, the surface temperature probe and the ground heat flux sensor. All these sensors are buried, except the surface temperature probe which is very close to the soil surface; in fact, this probe is laid on the soil surface and covered with a fine layer of sifted soil. The soil temperature probe has been placed at the same depth as the ground heat flux plate. Air temperature and air relative humidity are measured at two levels from an alternative air aspiration system as described by Cellier et al. (1993). In the figure, Tal is the air temperature at the lower level, Tah the one at the upper level, and $R H$ the relative humidity of the air measured in the captor chamber. To allow stabilization of air temperature and humidity sensors, no measurements of these parameters is made during the first $45 \mathrm{~s}$ following the inversion. The atmospheric pressure sensor is inside the station. Precise makes of instruments are specified in Table 3 
Table 3. Sensors used for the SBL study during the WELSONS experiment. Makes of sensors and errors for each sensor are also given. Temperature indicates soil as well as air temperature probes.
For wind speed, we give information on the cup anemometer coupled with wind vane only (CAW in Fig. 1) since other cup anemometers used for the wind profile were calibrated in a wind tunnel

\begin{tabular}{lll}
\hline Measurement & Sensors & Errors \\
\hline Net radiation flux & Net radiometer (REBS Q*7.1) & $3 \%$ \\
Ground heat flux & Soil heat fluxmeter (FRITSCHEN HFT-1) & $5 \%$ \\
Temperature & Pt resistance $1000 \Omega$ (Heraeus Sensor) & $0.1{ }^{\circ} \mathrm{C}\left(\right.$ at $\left.25{ }^{\circ} \mathrm{C}\right)$ \\
Relative humidity & Resistive captor (General Eastern RH2) & $2 \%, \mathrm{hysteresis}<1 \%$ \\
Atmospheric pressure & Pressure transmeter (VAISALA PTB101B) & $1 \mathrm{hPa}$ \\
Wind direction & Wind vane (NKE) & $3^{\circ}$ \\
Wind speed $\left(\mathrm{m} \mathrm{s}^{-1}\right)$ & Cup anemometer (NKE) & $0.3 \mathrm{~m} \mathrm{~s}^{-1}$ \\
\hline
\end{tabular}

during the two recordings (such as a cold gust of wind, fluctuations of atmospheric parameters due to the turbulence, non steady-state conditions, convection cells in the SBL for instance). The error on the air temperature gradient has been estimated experimentally by comparing values of the temperature gradient when temperatures at two heights were measured simultaneously, with the temperature gradient measured by the MGS (so making a time difference of $3 \mathrm{~min}$ ); the error value was $0.5 \mathrm{~K}$. The same work was not possible for the relative humidity gradient, and the error on the air specific humidity gradient was computed from errors on the $\mathrm{RH}$ gradient value $(1 \%)$, on the temperature probe of the $\mathrm{RH}$ captor $\left(0.1^{\circ} \mathrm{C}\right)$ and on the pressure captor $(1 \mathrm{hPa})$, given a lower limit of $0.3 \mathrm{~g} \mathrm{~kg}^{-1}$. Assuming that these errors on the gradients are randomized, an average over $N$ values reduces these statistical errors by a factor $1 / N^{1 / 2}$. In this study, 3-min measurements are averaged over $30 \mathrm{~min}$, so $N=10$, that involves $\sigma^{\Delta \theta}=0.2 \mathrm{~K}$ (rounded to the highest value) and $\sigma^{\Delta q}=0.1 \mathrm{~g} \mathrm{~kg}^{-1}$. The location of the sensors during the different periods of the 1997 WELSONS experiment is summarized in Table 4.

Table 4. Sensors' location during the different phases of the 1997 WELSONS experiment. Locations are quite similar between both MGS, so this table only presents the values for the station CT. The two latter phases are joined (phase II and phase III in Table 2) because no change occurred during this whole period

\begin{tabular}{lcc}
\hline Sensors & Height $(\mathrm{cm})$ & \\
\cline { 2 - 3 } & 19 June-15 July & $\begin{array}{c}\text { 16 July-25 } \\
\text { September }\end{array}$ \\
\hline Net radiation & 115 & 117 \\
Ground heat flux $^{\mathrm{a}}$ & 5 & 5 \\
High level of aspiration & 110 & 119 \\
Low level of aspiration & 21 & 30 \\
Cup anemometer and vane & 170 & 170 \\
Soil temperature & 5 & 5 \\
Surface temperature & 0.2 & 0.2 \\
Anemometer 1 & 25 & 28 \\
Anemometer 2 & 50 & 53 \\
Anemometer 3 & 100 & 118 \\
Anemometer 4 & 199 & 203 \\
Anemometer 5 & 399 & 402 \\
\hline
\end{tabular}

${ }^{\text {a }}$ Indicates that the value is related to depth

\section{Methodology}

On a bare soil, without advection effect, and assuming a state of equilibrium, fluxes at the soil surface must be true to the one-dimensional surface energy balance equation given by

$H+\lambda E=-(R n+G)$

all fluxes directed toward the surface are positive and vice versa.

A first method to compute fluxes in the SBL is based on the Monin-Obukhov similarity theory (e.g. Monin and Obukhov, 1954; Obukhov, 1946; Panofsky et al., 1960). Taking into account the water vapour effect on the atmospheric stability (e.g. Brook, 1978; Busch, 1973; Riehl et al., 1978) and different roughness lengths for momentum, heat and humidity (e.g. Brutsaert, 1975; Garrat and Hicks, 1973; Mascart et al., 1995; Wood and Mason 1991), the vertical profiles of wind, temperature and specific humidity for turbulent flows in the surface layer can be described by the following equations:

$$
\begin{aligned}
& u(z)=\frac{u_{*}}{k}\left[\ln \left(\frac{z}{z_{0 m}}\right)-\Psi_{m}\left(\frac{z}{L}\right)+\Psi_{m}\left(\frac{z_{0 m}}{L}\right)\right] \\
& \Delta \theta=\theta\left(z_{2}\right)-\theta\left(z_{1}\right)=\frac{\theta_{*}}{k}\left[\ln \left(\frac{z_{2}}{z_{1}}\right)-\Psi_{h}\left(\frac{z_{2}}{L}\right)+\Psi_{h}\left(\frac{z_{1}}{L}\right)\right] \\
& \Delta q=q\left(z_{2}\right)-q\left(z_{1}\right)=\frac{q_{*}}{k}\left[\ln \left(\frac{z_{2}}{z_{1}}\right)-\Psi_{q}\left(\frac{z_{2}}{L}\right)+\Psi_{q}\left(\frac{z_{1}}{L}\right)\right]
\end{aligned}
$$

with

$L=\frac{u_{*}^{2} \theta_{v}}{k g \theta_{v}^{*}} \approx \frac{u_{*}^{2} \theta(1+0.608 q)}{k g\left(\theta_{*}+0.608 \bar{\theta} q_{*}\right)}$

The roughness length $z_{0 m}$ used for this experiment is the local roughness length. This local roughness length is related to the geometry of the surface roughness elements, but should be seen as empirical coefficient in Eq. (2). It is different from the effective roughness length which represents the total effect of roughness elements in an inhomogeneous area (e.g. Beljaars and Holtslag, 1991; Garrat, 1980; Holtslag, 1984). Actually, our study only concerns a particular wind direction (between $285^{\circ}$ and $315^{\circ}$ ); and also the field is assumed to be homogeneous over $1 \mathrm{~km}$ upwind in this direction. The specific 
humidity was computed from the relative humidity measured by the MGS by using the W.M.O. formula (e.g. AFNOR, 1994), and expressed by

$$
\begin{aligned}
\ln e_{w}(T)= & -6096.9385 \cdot T^{-1}+21.2409642 \\
& -2.711193 \cdot 10^{-2} \cdot T+\cdots \\
& +1.673952 \cdot 10^{-5} \cdot T^{2}+2.433502 \cdot \ln T \\
& \text { with } 173.15 K<T<373.15 K
\end{aligned}
$$

Different forms of the stability functions have been derived and used in the literature (e.g. Beljaars and Holtslag, 1991; Businger et al., 1971; Dyer, 1974; Hogstrom, 1996). According to the recent review of Hogstrom (1988), the early formulations obtained by Paulson (1970), Dyer and Hicks (1970) and Hicks (1976) are still good approximations for an unstable surface layer. Their stability function can be used in this work $(z / L<0)$, and the formulations are given by

$\Psi_{m}=2 \ln \left(\frac{1+x}{2}\right)+\ln \left(\frac{1+x^{2}}{2}\right)-2 \arctan (x)+\frac{\pi}{2}$

$\Psi_{h}=2 \ln \left(\frac{1+y}{2}\right)$

where (Dyer, 1974),

$x=\left[1-15 \frac{z}{L}\right]^{1 / 4}$ and $\quad y=\left[1-15 \frac{z}{L}\right]^{1 / 2}$

Under stable conditions $(z / L<0)$, empirical data from Webb (1970) suggests

$\Psi_{m}=\Psi_{h}=-5 \frac{z}{L}$.

In both cases, we assumed equality between $\Psi_{h}=\Psi_{q}$.

The temperature and humidity scales are related to the sensible heat flux and latent heat flux as follows:

$H=c_{p} \rho u_{*} \theta_{v}^{*}$

$E=\rho u_{*} q_{*}$.

This first method is called the profile method. On the left-hand side of Eqs. (2)-(4), the horizontal wind speed, temperature difference and specific humidity difference can be directly determined by the MGS measurements. On the other hand, this method does not use the surface energy budget measurements $(R n$ and $G$ ). Due to limited accuracy in the observational data, the total flux $H+\lambda E$ computed by the profile method could be significantly different from the observed value of $R n+G$ and thus violate the energy balance equation.

A second method is the well-known Bowen ratio energy balance (BREB) method (e.g. Bowen, 1926; Fritschen and Simpson, 1989). Sensible and latent heat fluxes are determined from the energy balance equation and the expression of the Bowen ratio defined by $B=H / \lambda E$, with $H$ and $E$ expressed as a function of air temperature and humidity gradients as follows:

$$
\begin{aligned}
& H=-c_{p} \rho K_{h} \frac{\partial \theta}{\partial z} \\
& E=-\rho K_{q} \frac{\partial q}{\partial z} .
\end{aligned}
$$

So, assuming that $K_{h}$ and $K_{q}$ are equal, and that similarity laws for temperature and specific humidity are identical, an expression for the Bowen ratio is given as

$B \approx \frac{c_{p}}{\lambda} \cdot \frac{\Delta \theta}{\Delta q}$.

Knowing the Bowen ratio by measurement of the temperature and specific humidity gradients, such as the net radiation and the soil heat fluxes, we can express $H$ and $\lambda E$ as

$$
\begin{aligned}
& H=-\frac{R n+G}{1+1 / B} \\
& \lambda E=-\frac{R n+G}{1+B} .
\end{aligned}
$$

The energy balance is easily obtained by this way. The BREB method has generally been considered the most conservative and reliable all-weather technique for flux computations (e.g. Fritschen and Simpson, 1989; Priestley and Taylor, 1972). However, the BREB method does not use all the information in Eqs. (2)(10) provided by the similarity law, although Eq. (13) is derived from the ratio between Eq.(3) and Eq. (4) or from Eq. (10). It is also well known that the BREB method will become computationally unstable when the Bowen ratio is in the vicinity of -1 (e.g. Bertela, 1989). In this case, as we can see from Eq. (14), a small observational error in $R n+G$ or $B$ will entail very large errors in the computed fluxes. During the WELSONS experiment, the specific humidity difference may be very small with a very high relative error, that usually involved some uncertainty on the B value; for the use of the BREB method, this problem can be an important limiting factor in semiarid area (e.g. Cellier and Olioso, 1993).

Xu and Qiu (1997) combined these two methods into a variational method by considering that the roughness length is not a parameter to determine. They assumed that it does not change during a selected period, and determine it by another way. But with strong erosion events, it is possible that the high dust concentration in the first few centimetres of the SBL increases the $z_{0 m}$ value temporarily (Scott, 1995), and so the roughness length must be regarded as a parameter in our study. The variational method used here takes into account the system formed from Eqs. (2)-(4), and another equation to evaluate the mismatch $\delta$ between the computed $H+\lambda E$ and observed $R n+G$, given by

$\delta=R n+G+c_{p} \rho u_{*} \theta_{v}^{*}+\lambda \rho u_{*} q_{*}$

The roughness length appears only in Eq. (2) with the friction velocity, thus involving a high covariance between those parameters. In order to decrease the weight of the roughness length against the friction velocity, we added other equations expressing the 
difference of wind speed between two heights, and summed up by the following equation:

$\Delta u_{i}^{j}=u\left(z_{i}\right)-u\left(z_{j}\right)=\frac{u_{*}}{k}\left[\ln \left(\frac{z_{i}}{z_{j}}\right)-\Psi_{m}\left(\frac{z_{i}}{L}\right)+\Psi_{m}\left(\frac{z_{j}}{L}\right)\right]$

In Eq. (16), index " $i$ " is $1 \leq i \leq 5$ and index " $j$ " is $i<j \leq 5$. In fact, the best value of the friction velocity in the Eq. (16) is not necessarily the one for Eq. (2); so the minimum for the friction velocity is found by taking into account Eq. (2) and Eq. (16). This does not decrease the strong covariance between $u_{*}$ and $z_{0 m}$ in Eq. (2) but the computation of the friction velocity is more accurate, especially because the calculation of the roughness length is sensitive to errors on wind speed.

The Eq. (5) is the formulation of the MoninObukhov length, and universal functions must be explicitly expressed as a function of it in Eqs. (2)-(4), (16). Finally, in the system formed with Eqs. (2)-(4), (15), (16), there are four knowns, and 17 equations in total since five levels for the wind speed are available. The aim is then to find the scaling parameters $\left(u_{*}, \theta_{*}, q_{*}\right.$ and $z_{0 m}$ ) which solve this set of equations. A general method is to define a merit function (denoted $\chi^{2}$ ) which quantifies the square of deviations between the observed and calculated values to minimize them (Aloysius, 1978; Nieuwstadt, 1978; Xu and Qiu, 1997). We can express the merit function for our case by

$$
\begin{aligned}
\chi^{2}= & \sum_{i=1}^{4} \sum_{j>i}^{5} \frac{\left(\Delta u_{i}^{j}-\left(\Delta u_{i}^{j}\right)^{m}\right)^{2}}{\left(\sigma^{\Delta u}\right)^{2}}+\sum_{i=1}^{5} \frac{\left(u_{i}-u_{i}^{m}\right)^{2}}{\left(\sigma^{u}\right)^{2}} \\
& +\frac{\left(\Delta \theta-\Delta \theta^{m}\right)}{\left(\sigma^{\Delta \theta}\right)^{2}}+\frac{\left(\Delta q-\Delta q^{m}\right)}{\left(\sigma^{\Delta q}\right)^{2}}+\frac{\delta}{\left(\sigma^{\delta}\right)^{2}}
\end{aligned}
$$

with the different quantities defined in the list of symbols. The minimum of the $\chi^{2}$-function gives the optimal estimates of $\left(u_{*}, \theta_{*}, q_{*}, z_{0 m}\right)$. When standard deviations on measured quantities [represented by $\left(\sigma^{A}\right)^{2}$ terms] are known and taken into account in the merit function, it allows us to find optimized parameters with an error on their estimates. To make the minimum search, it is necessary to compute gradients components (the covariance matrix), partial derivatives of the $\chi^{2}$ function with respect to parameters. As the $\chi^{2}$-function depends on $\left(\sigma^{A}\right)^{2}$ terms, the value of these partial derivatives which determine the way to find the optimal solution and the minimum of the $\chi^{2}$-function, is strongly influenced by their presence. Therefore, the values of the standard deviation of the different quantities must be estimated as precisely as possible. The following estimated values, which derived from those already discussed in the previous section, were used: $\sigma^{\Delta u}=\sqrt{2} \cdot \sigma^{u}$ with $\sigma^{u}=0.1 \mathrm{~m} \mathrm{~s}^{-1}, \sigma^{\Delta \theta}=0.2 \mathrm{~K}, \sigma^{\Delta q}=0.1 \mathrm{~g} \mathrm{~kg}^{-1}$. As far as the $\sigma^{\delta}$ term is concerned, the computational programme calculates it at each step of the computation because of its dependence on the value of the net radiation flux (with $3 \%$ of error on it) and the soil heat flux $(5 \%$ of error). Moreover, errors on estimated parameters $\left(u_{*}, \theta_{*}, q_{*}, z_{0 m}\right)$ have to be taken into account, and are calculated at each step from the covariance matrix (they are initially set up at unity for the first step). For more details about $\chi^{2}$-distribution, its application and the use of covariance matrix for the optimisation of nonlinear problems, we can refer to Press et al. (1986). Marquardt's method has been used (mixture of the steepest descent and the Gauss-Newton technique) to find the minimum of this multivariate function (Marquardt, 1963; Nieuwstadt, 1978).

As far as the energy budget equation is concerned (see Eq. 1), soil heat flux has to be known at the surface. There are several methods to estimate the soil heat flux at the surface from temperature measurements and soil heat flux measured at different depths in the soil. The null-alignment method (Kimball and Jackson, 1975), the harmonic (Horton et al., 1983) and the finite difference method (Sharratt et al., 1992) are based on soil temperature measurements at several depths. The combination method (Massman, 1992) uses temperature with heat flux measurements. All those methods need volumetric heat capacity as well as thermal diffusivity (except the combination method for which only the volumetric heat capacity is required). By considering a soil temperature measured at the same depth as the heat flux plate and a surface temperature, Massman (1993) showed that it was possible to compute the soil heat flux at the surface by using a mathematical Kirschoff type transformation applied to the transient heat conduction equation. Passerat de Silans et al. (1997) during the HAPEXSahel experiment used this technique because of the impossibility to determine accurately the thermal properties (due to a vertical inhomogeneity of these). From the temperature and soil heat flux measurements in the soil, it has been possible during the WELSONS experiment to compute the ground heat flux at the surface, and to estimate the apparent thermal diffusivity, without knowing the thermal properties (they are always difficult to measure precisely in heterogeneous soil). This method involves the use of the Fourier series decomposition of the soil temperature, the surface temperature and the ground heat flux. For instance, the temperature wave can be expressed as (see list of symbols for the meaning of each term)

$$
T(z, t)=T_{0}(z)+\operatorname{Real}\left[\sum_{n=1}^{\infty} A_{n}(z) \cdot \exp \left[i \cdot\left(\omega \cdot n \cdot t+P_{n}\right)\right]\right]
$$

Because $A_{n}(z)$ is complex and a function of depth, it will contain the information on how the wave is damped and how its intrinsic phase is shifted as it propagates through the soil; on the other hand the associated phase $P_{n}$ is an arbitrary constant for any given harmonic and is usually assigned by convention. Passerat de Silans et al. (1997) used 18 harmonics to ensure a good fit between measured quantities and their Fourier series representation. If this operation is mathematically exact, it could produce some unrealistic values of the soil heat flux estimated at the surface. In fact, this Fourier represen- 
tation assumes the periodicity of parameters, and the use of too many harmonics may entail periods that are physically unrealistic. We used six harmonics for the Fourier decomposition, that gives a good description of the mean variation of the parameters (temperatures and soil heat flux) during daytime, but not so much during the night because the periodic assumption is less valid (since the strong periodic characteristic of the course of the sun during the day vanishes with darkness). This number of harmonics allows us to exclude the residual fluctuations for which the associated damping depth is unrealistic from a physical point of view (Frangi and Druilhet, 1988).

The scaling parameters $\left(u_{*}, \theta_{*}, q_{*}, z_{0 m}\right)$ can be obtained during wind profile measurements only. To evaluate fluxes over longer periods during similar meteorological conditions (Cierzo or wind direction in the WNW sector with a wind speed $>2 \mathrm{~m} \mathrm{~s}^{-1}$ ), the same method was used and applied to the FT database (measurement every $30 \mathrm{~min}$ ). However, we must modify the set of equations used, because the wind speed was measured at only one level, so Eq. (16) is removed. With temperature and specific humidity gradients, we have now four equations and four unknowns, and it is normally possible to find a solution. From Eq. (2) we can see that the roughness length will be optimized so that Eq. (2) is adjusted whatever the friction velocity value input may be, thus the friction velocity will be found to optimize Eqs. (3) and (4), and then the roughness length will be deduced by Eq. (2). To avoid this, the roughness length must not be a fitted parameter; so we assume that it is known from wind profiles measurements, and constant during the considered period. The optimized scaling parameters $\left(u_{*}, \theta_{*}, q_{*}\right)$ allow us to compute fluxes using Eq. (11).

\section{Data analysis}

We present some meteorological and microclimatological features (from FT database) for the whole 1997 experiment. Data values (collected every $3 \mathrm{~min}$ ) are averaged over $30 \mathrm{~min}$. They involve atmospheric pressure (measured at station 2 on the RT plot only), the net radiation flux, the temperature and relative humidity of the air, the soil and surface temperatures, the wind direction and speed. For all the figures, the time reference is universal time (UT). Some data are missing because of breakdowns of the MGS due to a malfunctioning of the solar panel. Most of data are from station number 1 installed on the CT plot; for soil and surface temperature, and ground heat flux, data are from station 2 because surface temperature probe at the station 1 was out of order in August. Data on rainfall measured by partner 2 (CSIC-EEAD, Table 1) are also presented. All these data give information about the general microclimatic conditions of the area studied. Thereafter data on the SBL are presented for the second period; they concern scaling parameters and the energy budget components, as well as a comparison of those quantities between the two plots.

\subsection{Rainfall, atmospheric pressure and relative humidity}

The 1997 summer was characterized by unusual rainfall with few big storms in June and August (as we can see by looking at the chronology of the atmospheric pressure in Fig. 3). To give exact information on the amount of rain (Fig. 4), we summarize here the main rainy days with their day-mean value of precipitation during this experiment: 28 June $\left(23 \mathrm{~mm}\right.$ day $\left.^{-1}\right)$, 2 July $\left(10 \mathrm{~mm} \mathrm{day}{ }^{-1}\right), 9$ July $\left(9 \mathrm{~mm} \mathrm{day}^{-1}\right), 16$ July

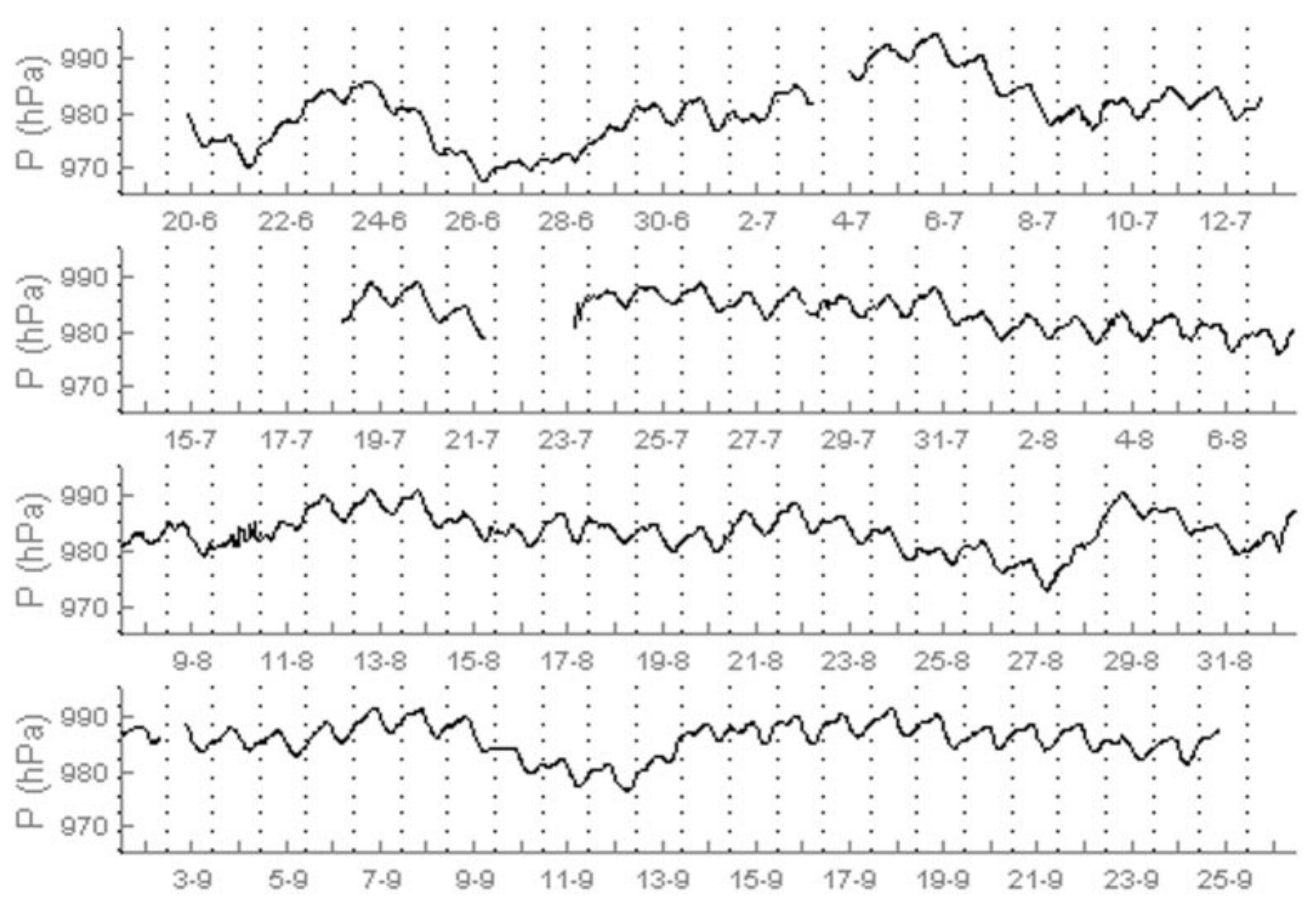

Fig. 3. Time series of the atmospheric pressure (in $\mathrm{hPa}$ ) for the 1997 WELSONS experiment. Data are from the station installed on the RT plot, and missing data in this time series (4 July, 13-18 July, 22-23 July and 3 September) are due to a malfunction of the solar panel causing power supply break to the MGS 


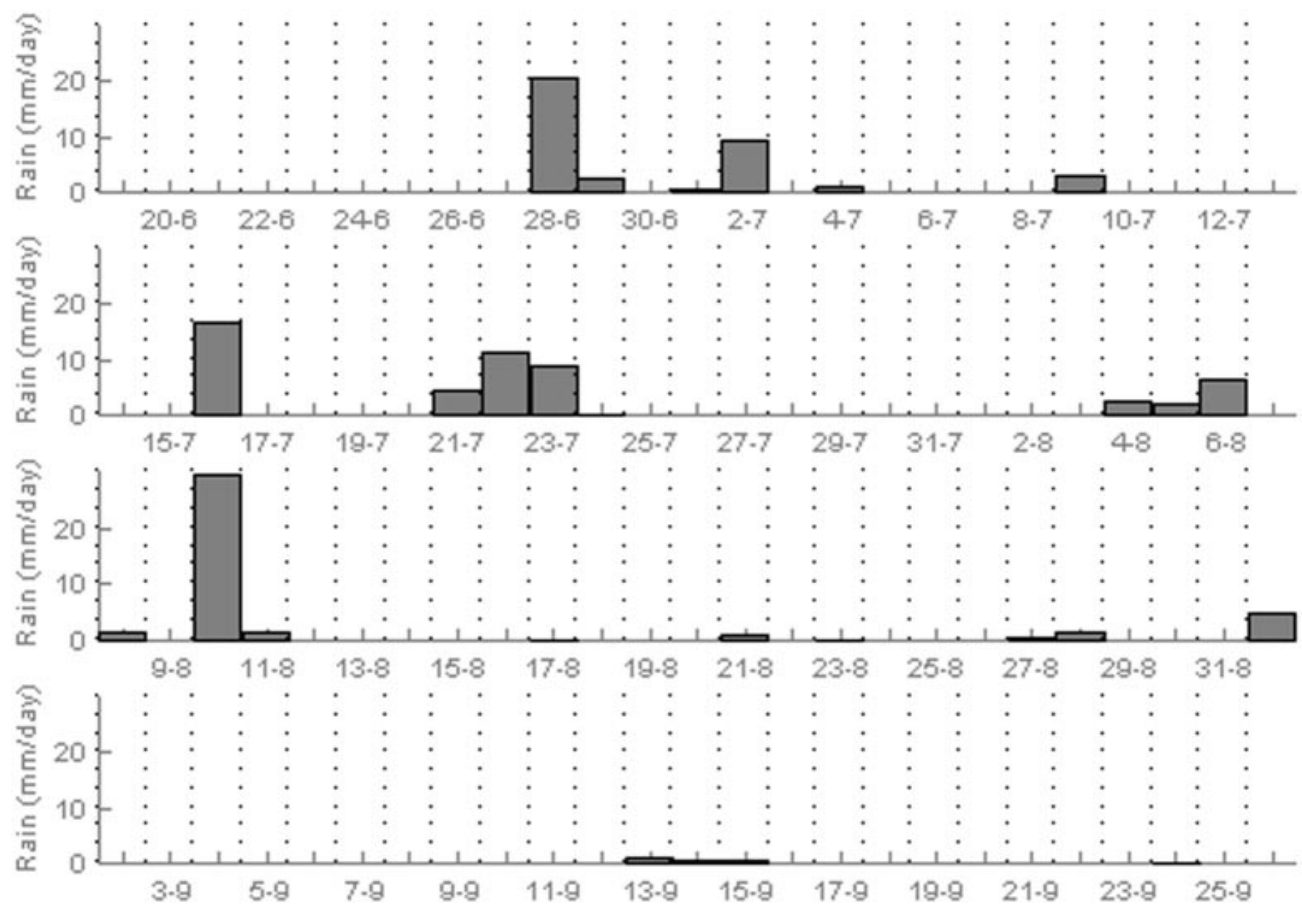

Fig. 4. Rainfall during the 1997 WELSONS experiment. It did not rain during the month before the beginning of the experiment on 19 June. Thus different states of soil humidity were encountered (wet soil, dry soil, very dry soil with crust formation)
(16 $\mathrm{mm} \mathrm{day}^{-1}$ ), 21-23 July (25 $\mathrm{mm}$ in all), 4-10 August (more than $42 \mathrm{~mm}$, with $30 \mathrm{~mm} \mathrm{day}^{-1}$ the 10 ), 1 September $\left(5 \mathrm{~mm} \mathrm{day}{ }^{-1}\right), 13-15$ September $(2 \mathrm{~mm}$ in all). It was a rainy period (23 rainy days with a total of $138 \mathrm{~mm}$ of rain recorded during these three and a half months), compared with the average annual rainfall in the area, about $380 \mathrm{~mm}$ for the 1941-1989 period (McAneney and Arrue, 1993). Rainfall strongly influences the energy budget by increasing the soil moisture, and consequently, the surface evaporation. Interactions between evaporation, soil moisture content and the SBL structure are quite complex, and the different stages in the drying of a field soil have been studied (e.g. Idso et al., 1974; Kobayashi et al., 1998). Surface evaporation can reduce the surface heating, and consequently, the evaluation of daytime boundary-layer development (e.g. Pan and Mahrt, 1986).

The atmospheric pressure ranges between 970 and $1000 \mathrm{hPa}$ for the whole experiment (Fig. 3). The lowest values correspond to rainy days and thundery showers, as seen by comparing Figs. 3 and 4. Atmospheric pressure has a periodic evolution: a decrease from $8 \mathrm{am}$ to $5 \mathrm{pm}$ and then it increases. The maximal amplitude in any day was $10 \mathrm{hPa}$ (on 28 August), and the smaller on 27 June $(2 \mathrm{hPa}$ only). The relative humidity (Fig. 5) varies widely throughout the day, from a few percent during daytime to more than $95 \%$ during the night. As with the other meteorological parameters, it displays a periodic evolution, with a maximum at around 6 am and a minimum around $3 \mathrm{pm}$. Its daily amplitude is minimum for the very dry period (until 27 June), or just after a rainy day. After a rainfall, during the next few days, the daily maximum relative humidity is constant whereas the minimum decreases.

\subsection{Wind conditions}

The compass card for the whole experiment is plotted on Fig. 6, and shows that it is extended in the NW-SE direction. Prevailing winds come from the $300^{\circ}$ sector (11\% of events), and more than $27 \%$ of wind events occurred in the $285^{\circ}-315^{\circ}$ sector, corresponding with the Cierzo direction. This wind blows over the whole of the north of Spain, and its characteristics are a main clearly defined direction (due to the specific relief of northern Spain as explained in Sect. 2.1.) and a high wind speed; it can blow for many days without abating. As far as the $105^{\circ}-135^{\circ}$ sector is concerned, Fig. 7 shows that wind speeds from this sector are lighter than those from the $285^{\circ}-315^{\circ}$ sector. Wind blowing from this direction corresponds generally to transition periods; its velocities are much slower than that of the Cierzo. So Cierzo is the strongest wind in addition to being the prevailing one in this part of the Ebro Valley. We can see the three main Cierzo events (with wind speed $>10 \mathrm{~m} \mathrm{~s}^{-1}$ ) that occurred during the 1997 WELSONS field campaign by looking at Fig. 8: 5 July, 17-18 July and 24-26 July. Lesser events ones happened on 22-23 June, 26-27 June, 11 and 28 of August, and 2, 10 and 13 of September. During Cierzo events, we can see that the behaviour of the wind is characterized by an increase of the wind from midnight to midday and a decrease later in the day. The increase of wind speed with a change of wind direction to the NW sector is observed six times out of eight after rainy days. An anticyclonic situation following a low-pressure system explains this behaviour in most cases, as shown by looking at the atmospheric pressure behaviour (Fig. 3). 

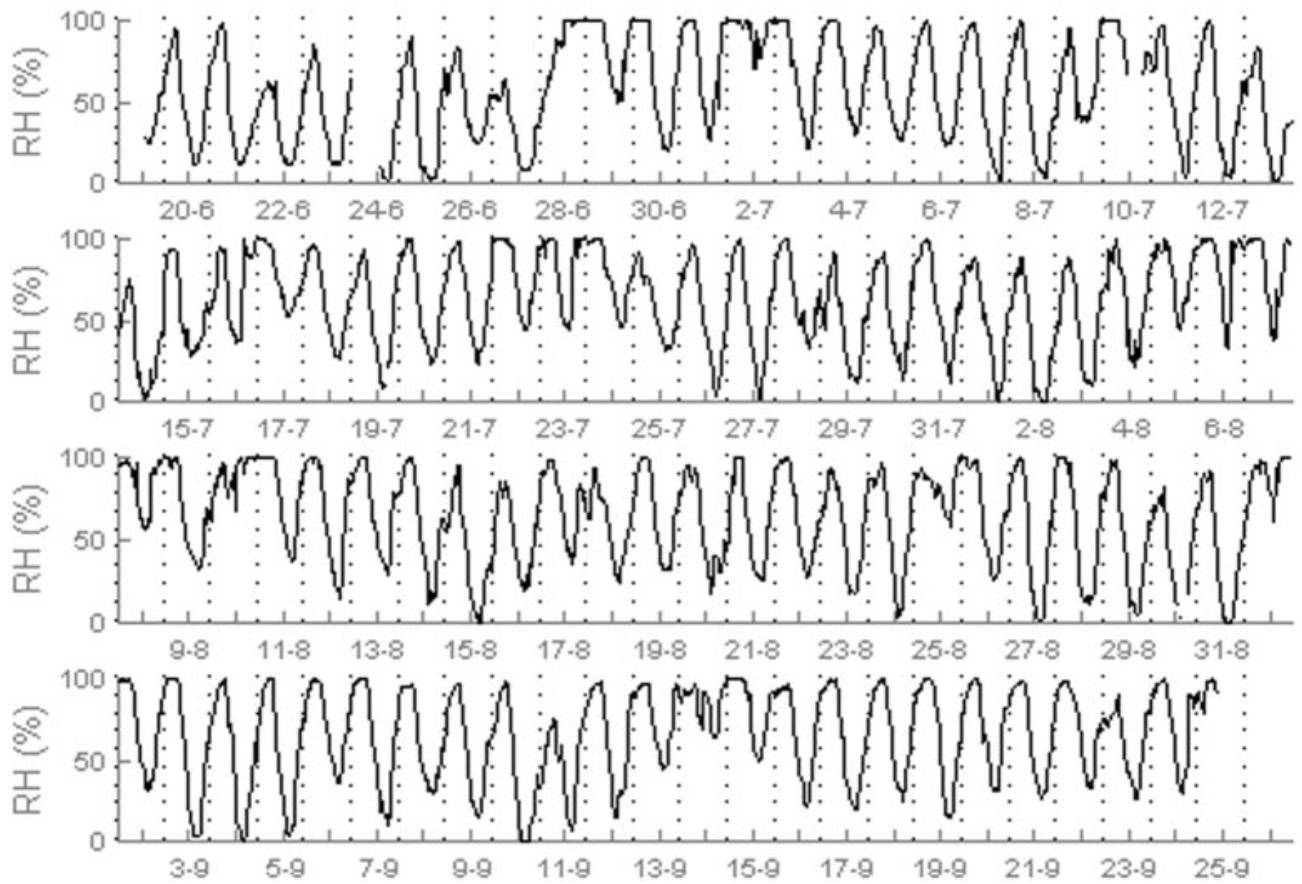

Fig. 5. Time series for the relative humidity for the 1997 WELSONS experiment. Values $>95 \%$ should not be used because the measurement range of the sensor extends only from $20 \%$ to $95 \%$

\subsection{Air, soil and surface temperatures}

It is important to bear in mind that the soil temperature is measured at $5 \mathrm{~cm}$ depth and the surface temperature very near the surface. We can see that air temperature (Fig. 9) can be very high during the day (more than $30{ }^{\circ} \mathrm{C}$ ), with a minimum of $10{ }^{\circ} \mathrm{C}$ at night, and so there is a range of $20^{\circ} \mathrm{C}$ (maximum of $21.7^{\circ} \mathrm{C}$ on 2 July). The highest temperature during the daytime varies between $36.4{ }^{\circ} \mathrm{C}$ (3 August) and $15.3{ }^{\circ} \mathrm{C}(28$ June), with a mean value of $30^{\circ} \mathrm{C}$, and the lowest between $8.6{ }^{\circ} \mathrm{C}$ (30 June)

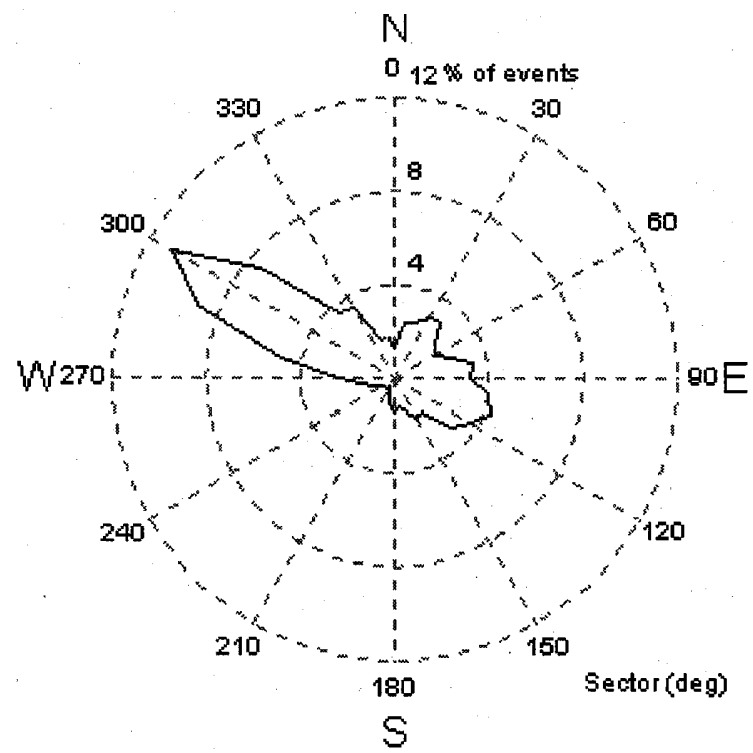

Fig. 6. Compass card for the whole 1997 WELSONS experiment. Wind vane data were classified according to $10^{\circ}$ sectors, and the radius in each cluster is proportional to the number of events measured in this sector (expressed in $\%$ of the total number of data) and $21.3{ }^{\circ} \mathrm{C}$ ( 23 June) with a mean value of $15^{\circ} \mathrm{C}$. Its evolution follows the diurnal cycle; air temperature increases between 6 am and $3 \mathrm{pm}$, and then decreases continuously. Soil and surface temperature are shown in Fig. 10. Surface temperature can be very high $\left(54{ }^{\circ} \mathrm{C}\right.$ on 25 June), with a range varying between $40{ }^{\circ} \mathrm{C}(2$ August) and $8.5^{\circ} \mathrm{C}$ (10 August). After a rainfall, the difference between the soil temperature and the surface
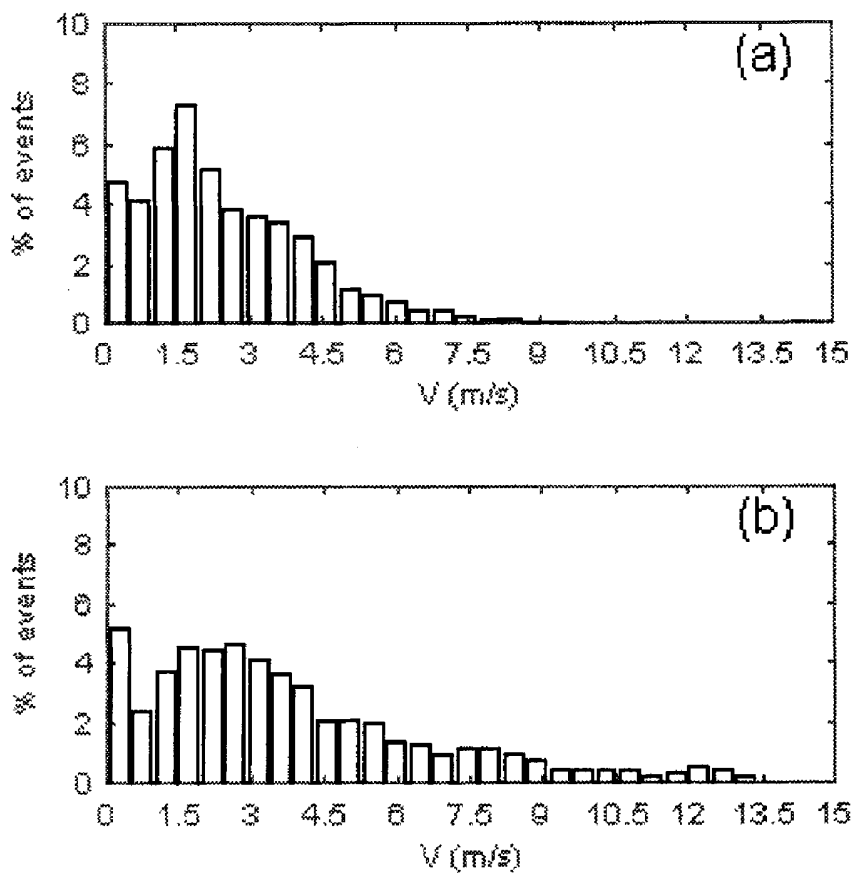

Fig. 7a, b. Wind speed distributions in different sectors: a for the $0^{\circ}-$ $180^{\circ}$ sector and $\mathbf{b}$ for the $180^{\circ}-360^{\circ}$ sector. The percentage of events was calculated from the total number of data recorded during the 1997 WELSONS experiment 


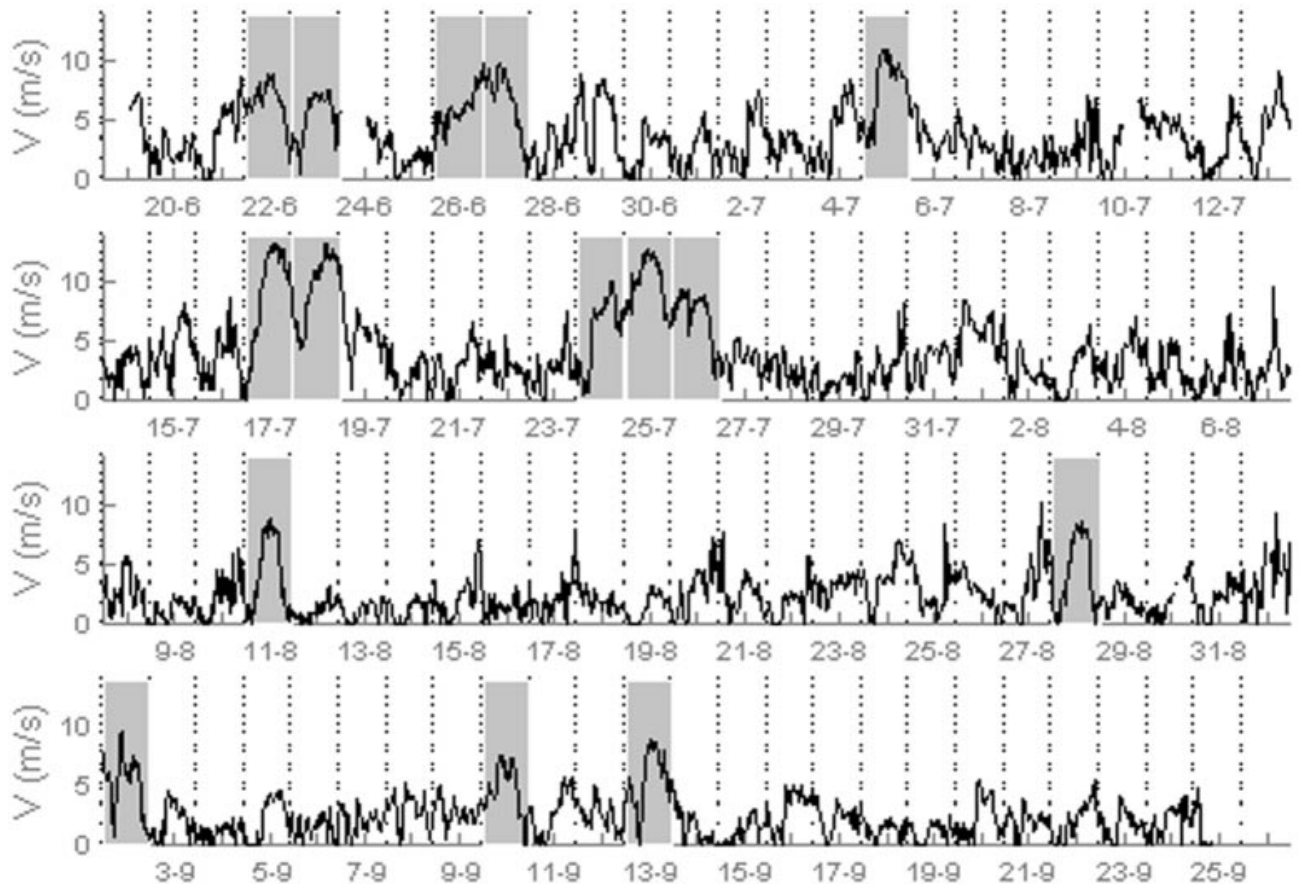

Fig. 8. Time series of wind speed for the whole 1997 WELSONS experiment. Data were averaged every $30 \mathrm{~min}$, and Cierzo days are shown in grey

temperature is low, and increases as the soil dries up. For instance, the computation of the apparent thermal diffusivity and the soil slab depth, by amplitude, phase, arctangent and logarithmic method (Horton et al., 1983), gives following results respectively from the 24 to 29 July (with high rainfall over the three days before): $0.49,0.41,0.31,0.25,0.17$ and $0.16 \mathrm{~mm}^{2} \mathrm{~s}^{-1}$ for the apparent thermal diffusivity, and 11.6, 10.6, 9.3, 8.3, 7.0 and $6.6 \mathrm{~cm}$ for the soil slab depth. Therefore the thermal characteristics of the soil may vary rapidly during the drying period (which is in keeping with the observations of Verhoef et al., 1995), and this behaviour strongly influences the partition of the energy budget. In those conditions, because of the low water content near the surface, vapour phase transfer may be assumed to be dominant (e.g. Jackson, 1974) and involves high values of the matric potential gradients (Scanlon, 1994).

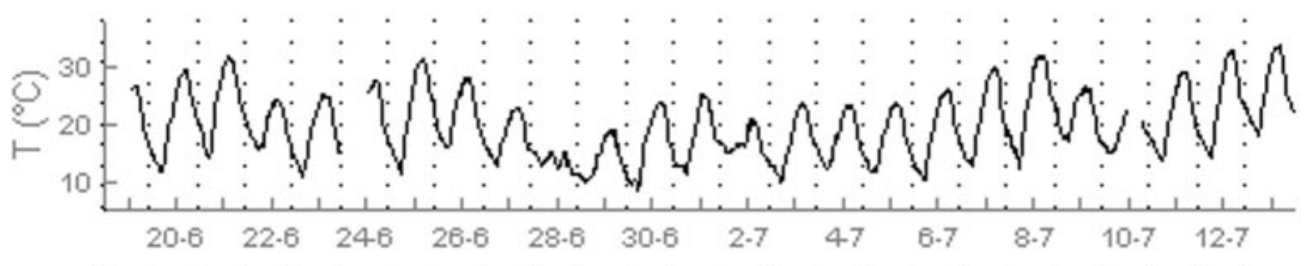

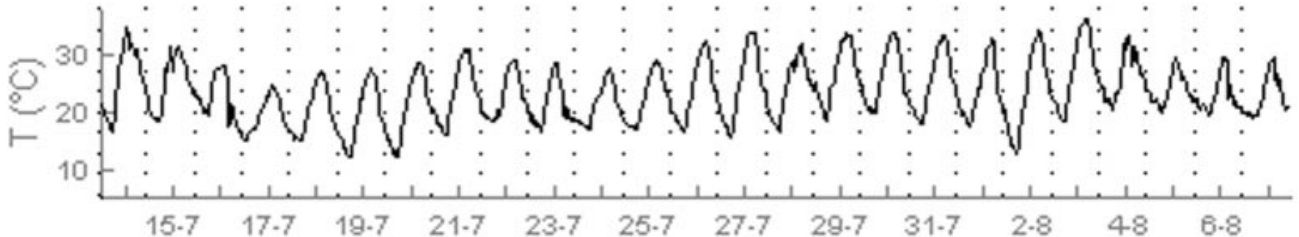

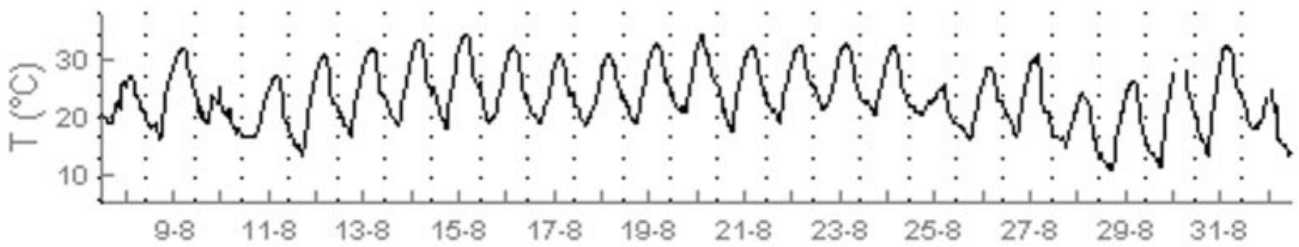

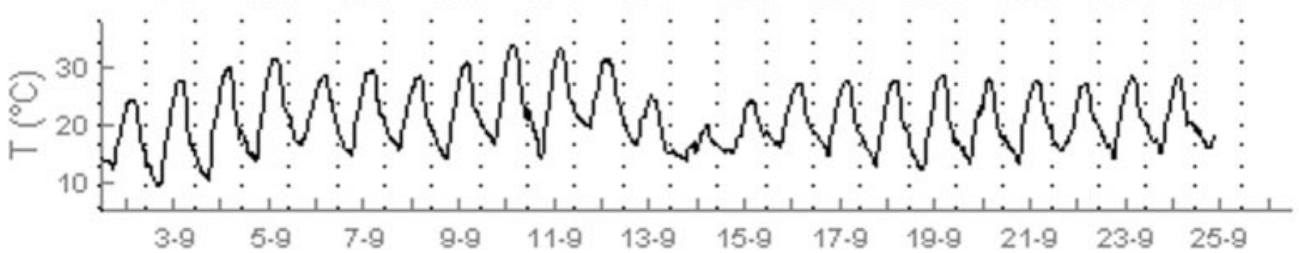

Fig. 9. Time series of air temperature for the 1997 WELSONS experiment measured at the high level on the MGS, corresponding with Tah in Fig. 1 (the exact height is given in Table 4) 

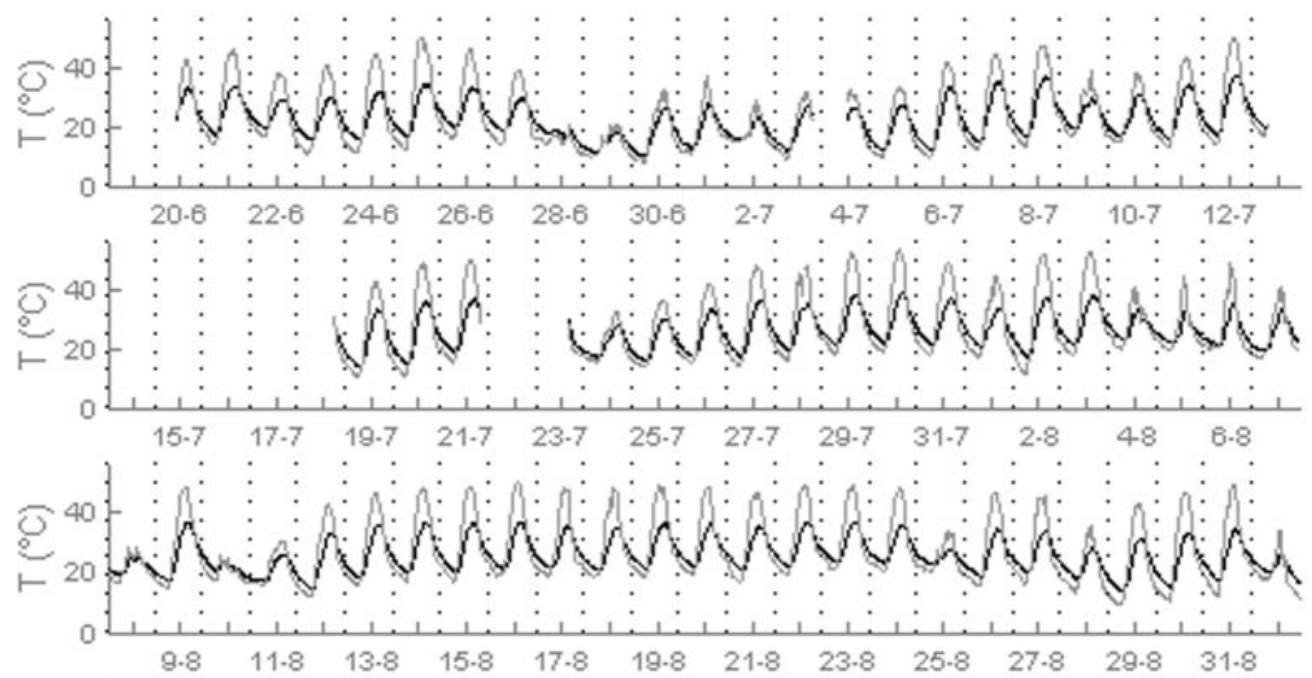

Fig. 10. Soil (black) and soil surface (grey) temperatures times series for the 1997 WELSONS experiment (see Table 4 for exact locations). Data are from the station installed on the RT plot, and missing data in this time series (4 July, 13-18 July, 22-23 July and 3 September) are due to a malfunction of the solar panel causing power supply failure to MGS

An interesting phenomenon is observed in the air as well as surface temperature with respect to wind speed. If we focus on days with dry conditions, such as the 20 27 June, we observe that air and surface temperatures decrease during Cierzo conditions, that prove the cold character of this air stream. Moreover, this wind results in a decrease of the relative humidity (Fig. 5), but this situation is only observed at the beginning of the experiment because the soil which is wet during the next Cierzo events a situation that prevents any conclusions being made.

\subsection{Soil heat flux}

The measured soil heat flux and its estimation at the surface are shown in Fig. 11. The former may be very high most of the time, reaching $-150 \mathrm{~W} \mathrm{~m}^{-2}$ during the day ( 1 July), and its maximal daily amplitude is greater than $200 \mathrm{~W} \mathrm{~m}^{-2}$ (1 July). The soil heat flux may be small on covered soil, and it is meaningless to correct it at the surface. In contrast it has an important effect on the energy balance for bare soils; this has been highlighted by Frangi and Druilhet (1988) during the ECLATS experi-

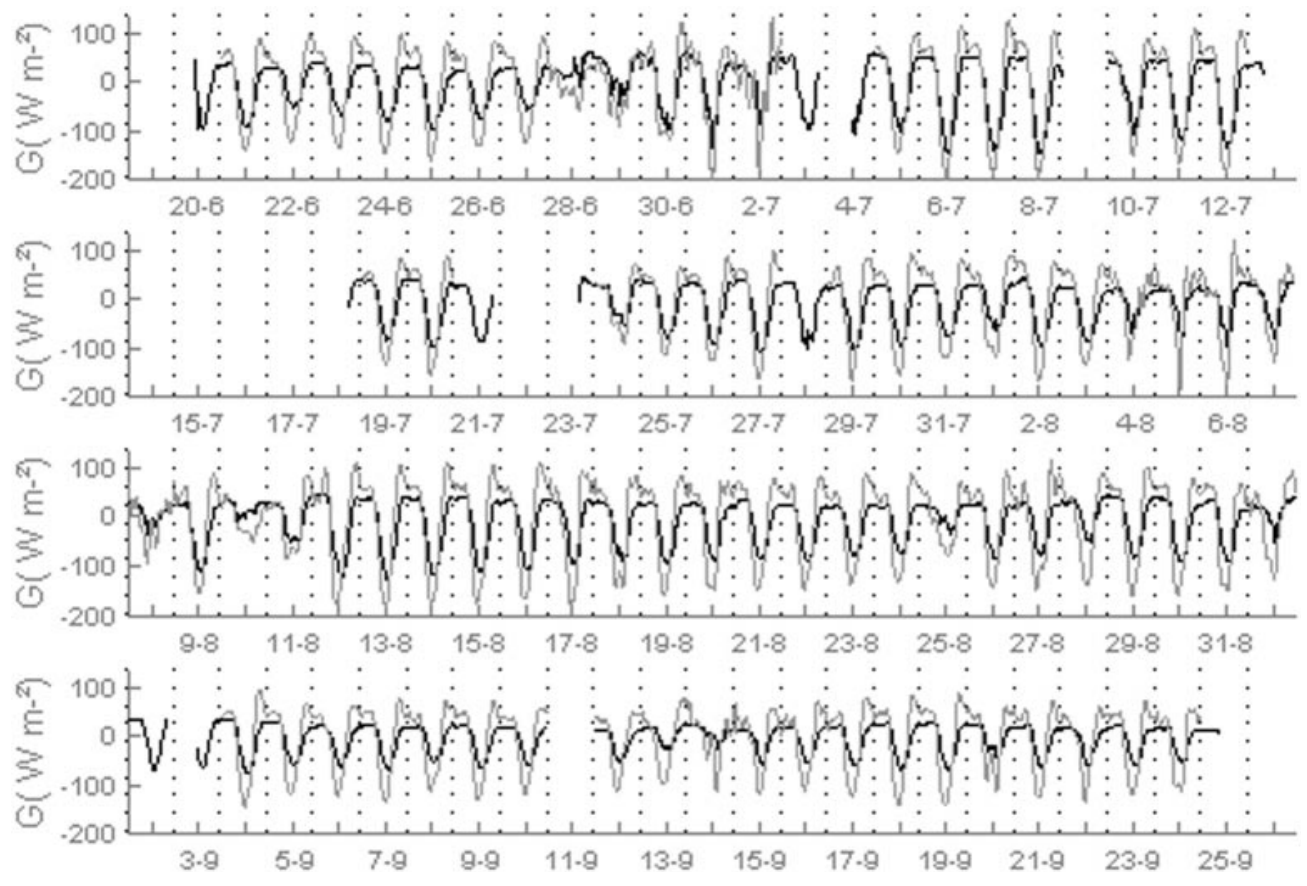

Fig. 11. Time series of the measured soil heat flux (black) and the calculated one at the surface (grey) for 1997 WELSONS experiment. As for soil and soil surface temperature, data come from the station installed on the RT plot and missing data are due to the same reasons, except on 9 July and the 11 September because a test on the soil heat flux plate was removed from the soil 
ment. For this reason, its estimation at the surface has been necessary to improve the energy budget closure, following the method explained in the methodology section. A trend analysis clearly shows a decrease of the daily minimum (from $\approx 50 \mathrm{~W} \mathrm{~m}^{-2}$ at the beginning of the experiment to $\approx 15 \mathrm{~W} \mathrm{~m}^{-2}$ at the end of September). That is observed also for the daily maximum, from $\approx-100 \mathrm{~W} \mathrm{~m}^{-2}$ at the beginning of the experiment to $\approx-60 \mathrm{~W} \mathrm{~m}^{-2}$ at the end of September, although this decrease was noticed only from the beginning of August for air and soil temperature. The estimated surface ground heat flux has the same behaviour. During daytime, it can reach $-190 \mathrm{~W} \mathrm{~m}^{-2}$ (6 July), with a minimum during the night of $130 \mathrm{~W} \mathrm{~m}^{-2}$ (on 2 July at $19 \mathrm{pm}$ ). Because of the phase shift, its maximum occurs around midday, before that of the soil heat flux.

\subsection{Net radiation flux}

The net radiation flux is plotted in Fig. 12. It ranges from $-80 \mathrm{~W} \mathrm{~m}^{-2}$ during the night to more than $500 \mathrm{~W} \mathrm{~m}^{-2}$ on clear days, reaching peaks of more than $600 \mathrm{~W} \mathrm{~m}^{-2}$ from time to time $\left(607 \mathrm{~W} \mathrm{~m}^{-2}\right.$ on 2 July after rain). The inversions of the flux occur around 6 am and $6 \mathrm{pm}$, with a maximum at midday of $400 \mathrm{~W} \mathrm{~m}^{-2}$ and a minimum of $-50 \mathrm{~W} \mathrm{~m}^{-2}$ at $8 \mathrm{pm}$. The daily mean value (Fig. 13) clearly shows a maximum between 27 and 30 June, which naturally corresponds with the summer solstice period. From this period onwards, we can observe a general decrease, with sudden rises. Figure 12 shows also that this peak is followed by a rapid decrease of the daily maximum of the net radiation flux a few days after. Viewing Fig. 12 and
Fig. 4, we notice an obvious relationship between those rises of the daily maximum of the net radiation flux and the rainfall (as on 11 August). Measurements of global radiation do not follow this feature and the net radiation sensor was checked every morning. On the other hand, the rise of the soil temperature gradient (related to the difference between the soil and the surface temperature) entails an increase of the ground heat flux. Moreover, it was not cloudy on all those days as shown by the net radiation flux aspect. As a consequence, this process can be explained by a different partition of the solar energy; a hypothesis expounding this phenomenon may be an increase of the longwave radiation flux from the ground since we can observe an increase of the surface temperature during this period, or an increase of albedo because of the decrease of the soil moisture, that would be in keeping with results of Idso et al. (1975). During this drying period, part of the energy is used for evaporation and not to increase the soil temperature (Verhoef et al., 1996). Because of the specific soil texture (silt loam), this high net radiation flux coupled with specific Cierzo conditions on 11 August leads to considerable evaporation, involving the formation of a crust on the soil surface, a natural property of soils to limit evaporation.

\section{Dynamics of the SBL: comparison between the two fields}

\subsection{Scaling parameters $\left(u_{*}, \theta_{*}, q_{*}, z_{0}\right)$}

We have chosen 25 July (DOY 205) to establish the comparison of the scaling parameters between the two

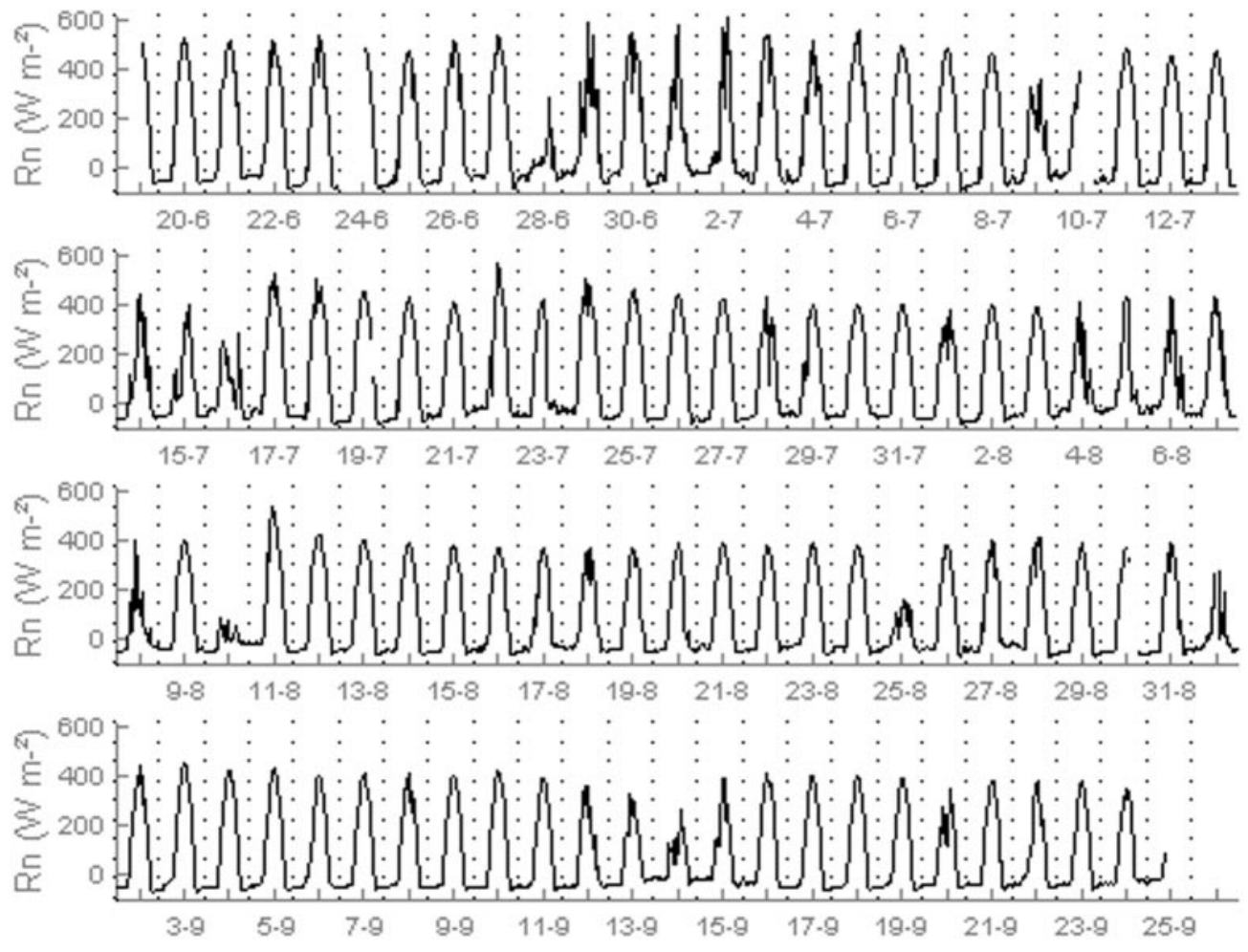

Fig. 12. Time series of the net radiation flux for the 1997 WELSONS experiment on the CT plot. Some data are missing due to the poor functioning of the solar panel 


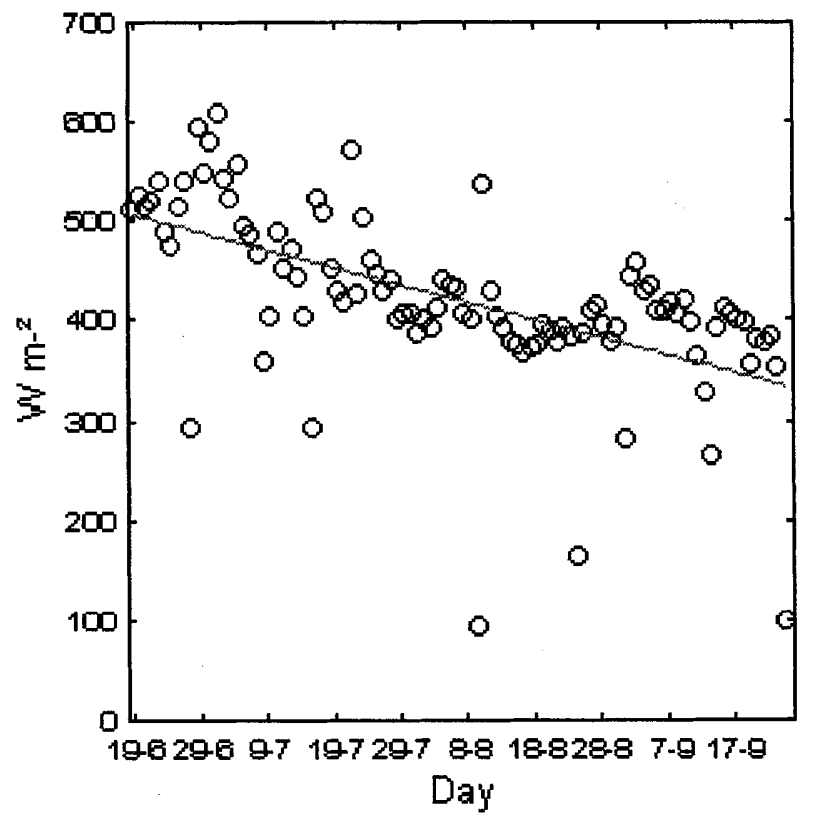

Fig. 13. Daily maximum of the net radiation flux over the whole experimental period. The least square line is in grey. The daily minimum (not shown) has an inverse trend

plots because of the exceptional recording time of the wind profile at $1 \mathrm{~Hz}$ under Cierzo conditions (from $2 \mathrm{pm}$ to midnight, so 36000 data at $1 \mathrm{~Hz}$ for the wind profile). DOY 201 till DOY 204 were rainy days $(25 \mathrm{~mm}$ in all), and consequently DOY 205 is characterized by high evaporation, which is favoured by the Cierzo conditions. As early as the following day (DOY 206), a crust formed, thus severely limiting any evaporation from this day onwards. Figure 14 shows the dynamic parameters for both stations.

The friction velocity is greater on the RT plot than on the $\mathrm{CT}$ one, that is in keeping with surface conditions on each plot and roughness length values (respectively $3.0 \pm 0.27 \mathrm{~mm}$ and $0.32 \pm 0.05 \mathrm{~mm}$ by averaging over the whole period of phase II). Although the friction velocity is lower on the CT plot than on the RT one, dust fluxes and saltation were observed only on the CT plot during the whole WELSONS experiment. This means that the threshold friction velocity is smaller on the CT plot, and consequently, that the chisel plough tillage provides possible wind erosion protection. This protection may be due to many factors such as an increase of the rough elements at the soil surface (as aggregates, etc.), stronger evaporation due to hydraulic properties (e.g. porosity, matric potential), etc. It is not possible to determine exactly which parameters control the wind erosion process in this area without complementary measurements (thermal and hydraulic characteristics), but this study clearly reveals the importance of tillage effect on the wind erosion process in this agricultural area.

During the daytime, the potential temperature scales between the two plots are quite different, but very less for the specific humidity scale. The absolute value of temperature scale is higher on the CT plot whereas specific humidity scale is lower there. Those differences seem to vanish during the night, but the specific humidity gradients are still negative, that involves the
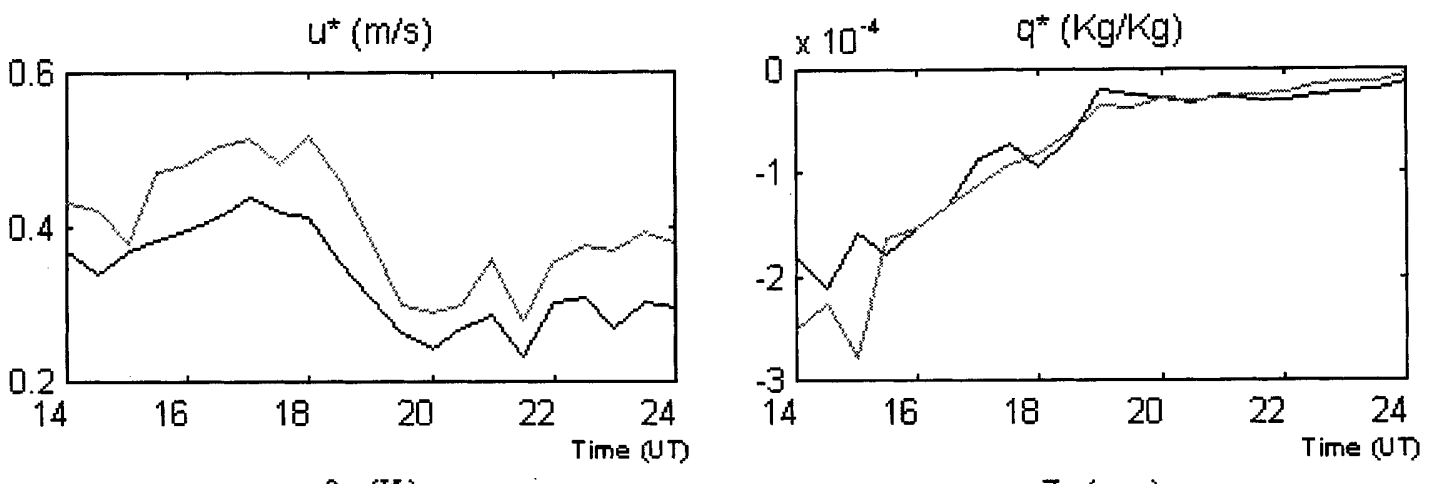

$\theta *(\mathrm{~K})$

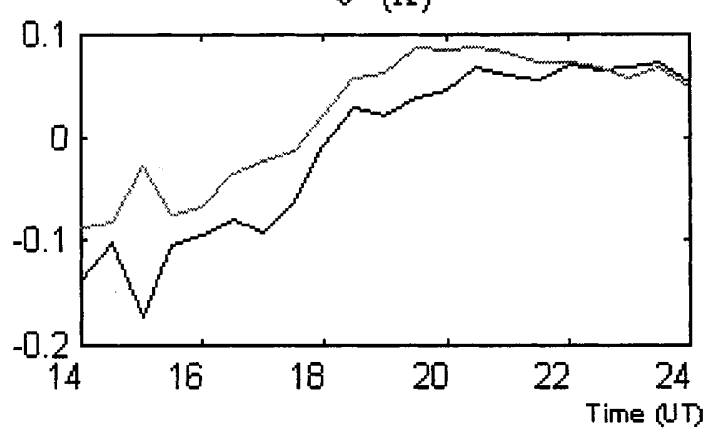

Fig. 14. Scaling parameters of the SBL for both plots CT plot (black) and the RT (grey) for 24 July (or DOY 205) were calculated every $30 \mathrm{~min}$. Plots show friction velocity (top left), potential temperature scale (lower left), specific humidity scale (top right), and roughness length (lower right) 

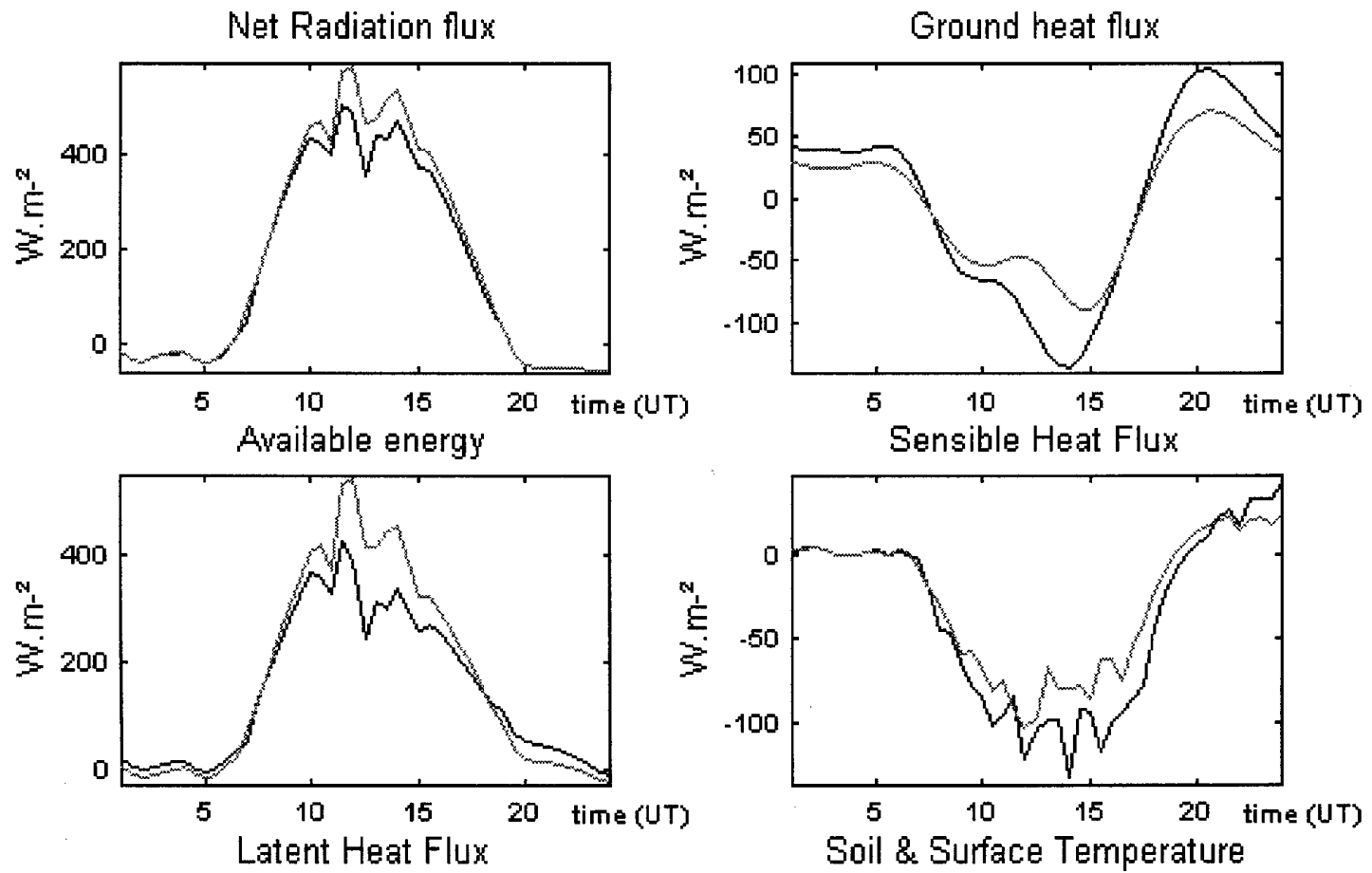

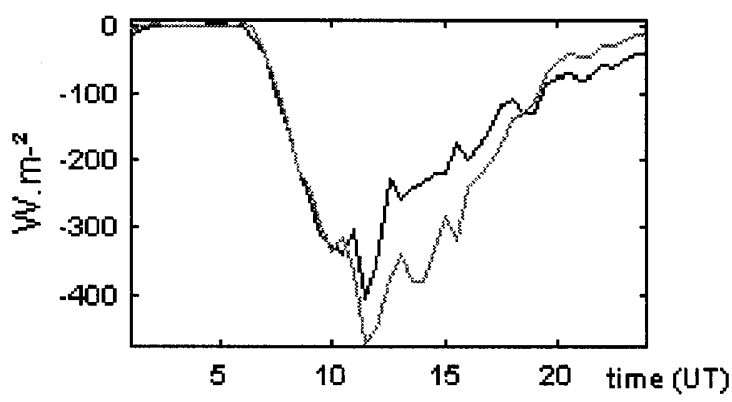

Fig. 15. An example of energy balance for the two fields, CT plot (black) line and RT plot (grey) for 25 July (DOY 205). Net radiation flux and ground heat flux plotted top-left and top-right respectively; the available energy and the sensible heat flux plotted middle-left and

negative sign for the scaling parameter $\left(q_{*}\right)$, and an upward latent heat flux. This phenomenon is unusual, and we will try to explain this in the next section by studying the energy budget during this day.

The friction velocity and the roughness length are important parameters. Their determination enables us to quantify the atmospheric dust fluxes from dust concentration gradients measured by the LISA partner. This is made by using the modified flux equation derived from Gillette (1977) to take into account stability effects. Moreover, these quantities are input data in dust emission models (Marticorena and Bergametti, 1995; Marticorena et al., 1996). So their determination during dust events is crucial to quantify wind erosion for a long-term prediction of soil losses, which is one of the aims of the WELSONS experiment.

\subsection{Energy budget}

The energy budget is presented on both plots for DOY 205. It has been calculated from air temperature and middle-right; latent heat flux is at bottom-left, and the soil and the surface temperatures at bottom-right. For soil and surface temperatures, dotted lines represent the soil temperature and solid lines the surface temperature

specific humidity gradients, and wind speed at one level (from the CAW, see Fig. 2). As assumed in the methodology section, the roughness length determined using the wind profile is presumed to be constant for a selected period. For phase II, its value has been computed (see previous section). For both stations, net radiation flux, soil heat flux, soil and surface temperatures, latent and sensible heat fluxes are plotted in Fig. 15.

During the night, the net radiation flux is quite similar on each plot (around $-30 \mathrm{~W} \mathrm{~m}^{-2}$ ). The net radiation flux curves have the same shape, but that on the RT plot is higher than on other field during the daytime, with a maximum difference of $110 \mathrm{~W} \mathrm{~m}^{-2}$ at midday. Peaks on the graphs indicate cloudy spells, due to storm remnants after the low-pressure system on 2123 July, this is unfortunately invisible in Fig. 3, but confirmed by the meteorological station at Zaragoza Airport. As it was a cloudy day, a mean value of $2 \mathrm{~h}$ for the difference between the two fields $\left(75 \mathrm{~W} \mathrm{~m}^{-2}\right)$ is more significant. This difference is high enough to be significant since it exceeds the errors of measurement. During 
the night, there is no revealing difference either on the net radiation flux or for surface temperatures between the two fields, and so the infrared emissivity of the two soils can be assumed equal. The maximal difference on surface temperature is $<2 \mathrm{~K}$ at midday, which involves a maximal difference on the upward infrared radiation fluxes of $<12 \mathrm{~W} \mathrm{~m}^{-2}$. On the other hand, the downward infrared radiation fluxes must be very close since the atmosphere above the experimental field is the same (the two stations are $200 \mathrm{~m}$ apart). Thus we can assume equal values of infrared emissivities of the soil surface, of the downward infrared fluxes, and of the upward infrared fluxes (because of the small difference around $12 \mathrm{~W} \mathrm{~m}^{-2}$ ). Then we can express the net radiation difference between the two plots by the following equation (see the list of symbols for significance of the different terms):

$R n_{C T}-R n_{R T}=\left(a_{R T}-a_{C T}\right) R g-\varepsilon \sigma\left(T s_{C T}^{4}-T s_{R T}^{4}\right)$.

By taking into account radiation data over the whole day, we can find the value of the albedo difference by the least-square method. With an emissivity of $0.90 \pm 0.09$, which is a wide range, we obtain a difference $\left(a_{R T}-a_{C T}\right)$ between the two plots of $-0.06 \pm 0.01$, that is to say that the albedo on the CT plot is greater than on the RT. That involves a difference of $64 \mathrm{~W} \mathrm{~m}^{-2}$ (average value over $2 \mathrm{~h}$ ) by using Eq. (19), which is consistent with the observed value of $75 \mathrm{~W} \mathrm{~m}^{-2}$. This technique works quite well on clear days; here the equal value of downward longwave radiation fluxes is confirmed by estimating it on each plot with the Idso formulae (1981), since mean air temperature and mean specific humidity are very close to each other. For DOY 205, which is a cloudy day, the assumption concerning the balance of the downward infrared fluxes may not be true.

The ground heat flux is quite different between the two fields. At the CT plot, its value is around $40 \mathrm{~W} \mathrm{~m}^{-2}$ from midnight to sunrise, while it is $50 \mathrm{~W} \mathrm{~m}^{-2}$ on the RT plot. During daytime, we can observe a little phase shift; the maximum on the $\mathrm{CT}$ plot is $-135 \mathrm{~W} \mathrm{~m}^{-2}$ around $2 \mathrm{pm}$, and $-90 \mathrm{~W} \mathrm{~m}^{-2}$ around $2.30 \mathrm{pm}$ on the RT plot, giving a difference of $65 \mathrm{~W} \mathrm{~m}^{-2}$. The ground heat flux changes sign well before sunset (more than $2 \mathrm{~h}$ ). The ground heat flux is greater near to sunset than later at night. This is related to the fact that the ground has some thermal inertia, leaving the ground temperature warmer than the air temperature over the few hours near sunset when the ground heat flux has already become positive. During this short period, the ground is loosing heat not only to the cooling air, but also by radiation to space; this causes the temporary bulge in the ground flux at night. Later in the night, the ground finally becomes colder than the air, allowing some of the heat lost to space to be replaced by conduction from the air.

As a consequence of the smaller net radiation flux and the higher ground heat flux on the CT plot than on the RT one, the available energy at the soil surface $(R n+G)$ is greater on the RT plot (with a maximum difference of $170 \mathrm{~W} \mathrm{~m}^{-2}$ at midday), and is so for the sum of the sensible heat and the latent heat fluxes as well.

For those fluxes, we can observe peaks, mainly due to the uncertainty in the air temperature and specific humidity gradients. The partitioning of the available energy into sensible and latent heat fluxes is quite different on each plot. The sensible heat flux is higher on the $\mathrm{CT}$ plot, with a maximum difference $\approx 40 \mathrm{~W} \mathrm{~m}^{-2}$ around midday, whereas the latent heat flux is greater on the RT plot during the daytime, in contrast to the soil heat flux. On both plots, the sensible heat flux is much smaller than the latent heat flux: most of the available energy is used to evaporate soil humidity, and this process is more effective on the RT plot. That explains the smaller ground heat flux and the lower surface temperature on the RT plot than on the other. Note that the soil heat fluxes react earlier than the sensible and latent heat fluxes to the net radiation change at sunrise, since the soil warms up more rapidly than the atmosphere. At the end of the day, the latent heat flux does not change its sign, and is still important $\left(\approx-40 \mathrm{~W} \mathrm{~m}^{-2}\right)$, whereas the sensible heat flux is positive $\left(\approx 30 \mathrm{~W} \mathrm{~m}^{-2}\right)$, which is an unusual behaviour. We know that during the night, a transfer of energy occurs between the atmosphere and the soil by conduction. A hypothesis for this relatively high latent heat flux during the night would be that part of this energy lost by the atmosphere is consumed to evaporate a small part of the soil humidity. Moreover, the high air temperature $\left(>20^{\circ}\right.$ during this night) does not allow condensation of the air humidity (proved by the relative humidity around $80 \%$ ), and the dry Cierzo conditions may favour this process. The use of soil-atmosphere transfer models, such as the SVAT model (Blyth, 1995; Franks et al., 1997; Calvet et al., 1998) or SiSPAT model (Boulet et al., 1996; Braud et al., 1995) can be useful to describe such processes more precisely by considering thermal and hydrological soil properties.

\section{Conclusion}

We have illustrated the work of the WELSONS project devoted to study wind erosion in the European Community. Results of this project are from three measurement campaigns carried out during summers 1996, 1997 and 1998 in northern Spain. Data recorded on two fields with different tillage modes (conventional tillage, CT, and reduced tillage, RT) over each summer allowed us to study the wind erosion process in this region, and its relation to tillage practice. From this study, original data on dynamics and energy budget of the SBL for a representative semiarid area in the northern Spain were recorded. Time series reveal that most of parameters follow a harmonious evolution during the day in keeping with the diurnal cycle, and present a great range between night and day. The two tillage methods induce differences in both dynamics characteristics and energy budget partition between the two fields, by modifying both surface and soil characteristics. An analysis of the friction velocity and roughness length 
shows that the RT is able to reduce wind erosion by an increase of soil aggregation, roughness length and threshold friction velocity. As a first conclusion, the wind erosion process in this region is not a continuous phenomenon: the threshold friction velocity will be often exceeded because of gusty winds blowing over this region, but this is only during very short periods. Complementary measurements of dust and saltation fluxes, such as hydrological properties of the soil should quantify its efficiency. The friction velocity and the roughness length allow us to compute dust fluxes from dust gradients measured by the LISA (partner 1). They will be also used to test an emission model and to calibrate it. Finally, a prediction of the long-term losses in this area will be possible. As far as energy budget is concerned, the first results show a different partitioning of the energy at the surface. The sensible heat flux and the net radiation flux are higher on the RT plot, whereas the ground heat flux and the latent heat flux are higher on the CT plot, because of tillage effects on the soil structure and surface characteristics. In spite of the low humidity gradients, the method used enables us to compute the energy budget and dynamic scaling parameters of the SBL during WELSONS experiment. Finally, WELSONS data can be useful to test coupled air/soil models. Further developments will be the association of a wind erosion model with a SVAT model, since dust emissions can influence the energy budget and the structure of the SBL. All data obtained during this experiment from the different partners will be available in a WELSONS database freely accessible to the scientific community.

Acknowledgements. This work was sponsored by the European Commission-Environment and Climate Programme DG XII under contract $\mathrm{n}^{\circ}$ ENV4-CT95-0182. The authors wish to thank Dr. P. Mestayer and M. J.-M. Rosant of the Ecole Centrale de Nantes for their help during the anemometer calibration experiment. We are grateful to J.-L. Arrue from the CSIC (partner 2 of the WELSONS project) for his collaboration, which allows us to present the rainfall data. Reviewers are gratefully acknowledged for their detailed inspection of the previous version of this paper, as Dr. S. Jacquemoud and Dr. H. Roberts for their advice on the first manuscript.

Topical Editor J.-P. Duvel thanks two referees for their help in evaluating this paper.

\section{List of symbols}

$\begin{array}{ll}a & \begin{array}{l}\text { Soil albedo } \\ A_{n}\end{array} \\ B & \begin{array}{l}\text { Complex amplitude of the temperature wave for the } \\ n \text {th harmonic }\left({ }^{\circ} \mathrm{C}\right)\end{array} \\ & \text { Bowen ratio } \\ c_{p}=1004.67 & \begin{array}{l}\text { Specific heat for air at constant pressure }\left(\mathrm{J} \mathrm{kg}^{-1} \mathrm{~K}^{-1}\right) \\ e_{w}(\mathrm{~T})\end{array} \\ & \begin{array}{l}\text { Saturation vapour pressure at the temperature } T \\ (\mathrm{~Pa})\end{array} \\ E & \text { Evaporation flux }\left(\mathrm{kg} \mathrm{m}^{-2} \mathrm{~s}^{-1}\right) \\ k=0.4 & \text { Von Kármán's constant } \\ g=9.81 & \text { Gravity acceleration }\left(\mathrm{m} \mathrm{s}^{-2}\right) \\ G & \text { Surface soil heat flux }\left(\mathrm{W} \mathrm{m}^{-2}\right) \\ H & \text { Sensible heat flux }\left(\mathrm{W} \mathrm{m} \mathrm{m}^{-2}\right) \\ i & \text { The complex number }(-1)^{1 / 2} \\ K & \text { Turbulent exchange coefficients for heat and water } \\ \text { vapour }\left(\mathrm{m}^{2} \mathrm{~s}^{-1}\right)\end{array}$

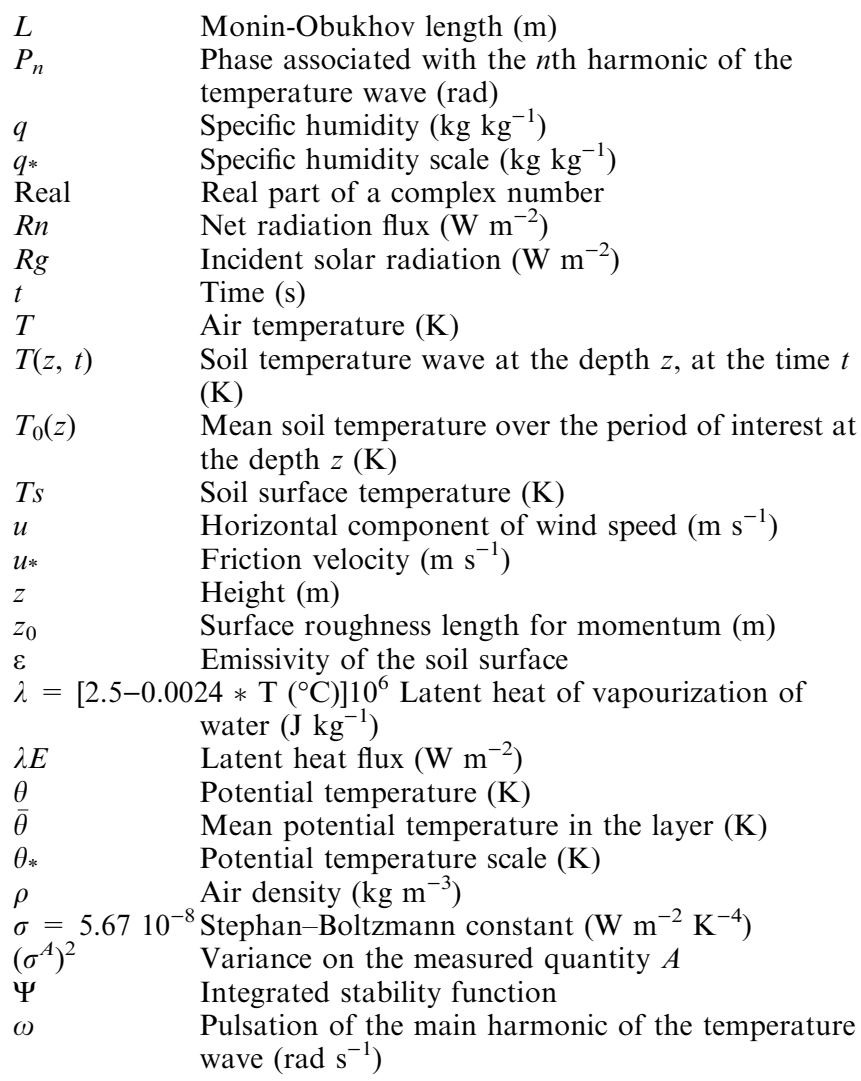

\section{References}

AFNOR, Norme NFX 15-110: Mesure de l'humidité de l'air paramètres hygrométriques, $14 \mathrm{pp}, 1994$.

Aloysius, K. L., A method for determining flux parameters in the absence of a temperature profile, Bound.-Layer Meteorol., 15, 195-204, 1978.

Armbrust, D. V., W. S. Chepil, and F. S. Siddoway, Effect of ridges on erosion of soil by wind, Soil Sci. Soc. Am. J., 28, 557-560, 1964.

André, J. C., J. P. Goutorbe, and A. Perrier, HAPEX-MOBILHY, a hydrologic atmospheric experiment for the study of water budget and evaporation flux at the climatic scale, Bull. Am. Meteorol. Soc., 67, 138-144, 1986.

Barrow, C. J., Land degradation: development and breakdown of terrestrial environments, (Ed.) Cambridge University Press, Cambridge, 44, 400 pp, 1991.

Beljaars, A. C. M., and A. A. M. Holtslag, Flux parameterization over land surfaces for atmospheric models, J. Appl. Meteorol., 30, 327-341, 1991.

Bertela, M., Inconsistent surface flux partitioning by the Bowen ratio method, Bound.-Layer Meteorol., 49, 149-167, 1989.

Biel, A., and L. Garcia de Pedraza, El clima en Zaragoza y ensayo climatologico para el valle del Ebro, Ministerio del Aire, Servicio 
Meteorologico National. Publicaciones Ser. A (Memorias) 36, Madrid, 57 pp, 1962.

Bisal, F., and J. Hsieh, Influence of moisture on erodibility of soil by wind, Soil Sci., 102, 143-146, 1966.

Blyth, E. M., Using a simple SVAT scheme to describe the effect of scale on aggregation, Bound.-Layer Meteorol., 72, 267-285, 1995.

Bolle, H. J., and co-authors, EFEDA: European field experiment in a desertification threatened area. Ann. Geophysicae, 11, 173189, 1993.

Boulet, G., I. Braud, and M. Vauclin, Study of the mechanisms of evaporation under arid conditions using a detailed model of the soil-atmosphere continuum. Application to the EFEDA I experiment, J. Hydrol., 193, 114-141, 1996.

Bowen, I. S., The ratio of heat losses by conduction and by evaporation for any water surface, Physical Rev., 27, 779-787, 1926.

Bowers, S. A., and R. J. Hanks, Reflection of radiant energy from soils, Soil Sci., 100, 130-138, 1965.

Braud, I., A. C. Dantas-Antonio, M. Vauclin, J. L. Tony, and P. Ruelle, A simple soil-plant-atmosphere transfer model (SiSPAT): development and field verification, J. Hydrol., 166, 213-250, 1995.

Brook, R. R., The influence of water vapor fluctuations on turbulent fluxes, Bound.-Layer Meteorol., 15, 481-487, 1978.

Brutsaert, W., The roughness length for water vapor, sensible heat, and others scalars, J. Atmos. Sci., 32, 2028-2031, 1975.

Busch, N. E., On the mechanics of atmospheric turbulence, in Workshop on Micrometeorology, Ed. D. A. Haugen, American Meteorological Society, Boston, Massachusetts, 392 pp, 1973.

Businger, J. A., J. C. Wyngaard, Y. Izumi, and E. F. Bradley, Fluxprofile relationships in the atmospheric surface layer, J. Atmos. Sci., 28, 181-189, 1971.

Calvet, J.C., and co-authors, An interactive vegetation SVAT model tested against data from six contrasting sites, Agric. For. Meteorol., 92, 73-95, 1998.

Cellier, P., and A. Olioso, A simple system for automated longterm Bowen ratio measurement, Agric. For. Meteorol., 66, 8192, 1993.

Chepil, W. S., Properties of soil which influence wind erosion: IV. State of dry aggregate structure, Soil Sci., 72, 387-401, 1951.

Chepil, W. S., Influence of moisture on erodibility of soil by wind, Soil Sci. Soc. Am. Proc., 20, 288-292, 1956.

Conacher, A. J., and M. Sala, Land degradation in Mediterranean environments of the world: nature and extent, causes and solutions, Ed., Wiley J, Chichester, 491 pp, 1998.

De Angelis, M., N. I. Barkov, and V. N. Petrov, Aerosol concentrations over the last climatic cycle $(160 \mathrm{kyr})$ from an Antarctic ice core, Nature, 325, 318-321, 1987.

De Ploey, J., A. V. Auzet, H. R. Bork, N. Misopolinos, G. Rodolfi, M. Sala, and N. G. Silleos, Soil erosion map of Western Europe, Catena, Cremlingen-Destedt, Germany, 1989.

Dregne, H. E., Soils of arid regions, Elsevier Scientific, Amsterdam, $237 \mathrm{pp}, 1976$.

Druilhet, A., and A. Tinga, Présentation de l'expérience ECLATS. La météorologie, Serie VI, 29-30, 203-212, 1982.

Durand, P., J. P. Frangi, and A. Druilhet, Energy budget for the Sahel surface layer during the ECLATS experiment, Bound.Layer Meteorol., 42, 27-42, 1988.

Dyer, A. J., A review of flux-profile relationships, Bound.-Layer Meteorol., 7, 363-372, 1974.

Dyer, A. J., and B. B. Hicks, Flux-gradient relationship in the constant flux layer, Qt. J. R. Meteorol. Soc., 96, 715-721, 1970.

Eppink, L. A. A. J., and W. P. Spaan, Agricultural wind erosion control measures in the Netherlands, in, Soil erosion protection measures in Europe, Eds. U. Schwertmann, R. J. Rickson, and K. Auerswald, Soil Technology Series, 1, Catena, Cremlingen, Germany, 1-13, 1989

Frangi, J. P., and A. Druilhet, Rôle du sol dans les échanges d'énergie dans la couche de surface sahélienne, Ann. Geophysicae, 6, 81-88, 1988.
Frangi, J. P., and P. Poullain, Un système d'acquisition haute vitesse de données dynamiques, associé à une station de mesure du bilan d'énergie de surface, Sécheresse, 8, 70 p, 1997.

Frangi, J. P., C. Garrigues, F. Haberstock, and F. Forest, Evapotranspiration and stress indicator through Bowen ratio method, in Proc. of the Int. Conf. on Evapotranspiration and Irrigation Scheduling, November 3-6, San Antonio, Texas, USA, 800-805 pp, 1996.

Franks, S. W., K. J. Beven, P. F. Quinn, and I. R. Wright, On the sensitivity of soil-vegetation-atmosphere transfer (SVAT) schemes: equifinality and the problem of robust calibration, Agric. For. Meteorol., 86, 63-75, 1997.

Frielinghaus, M., Present state of erosion research in East Germany, Eur. Soc. Soil Cons. (ESSC) Newslett., 1, 3-6, 1991.

Fritschen, L. J., and J. R. Simpson, Surface energy and radiation balance systems: general description and improvements, J. Appl. Meteorol., 28, 680-689, 1989.

Fryrear, D. W., and A. Saleh, Field wind erosion: vertical distribution, Soil Sci., 155, 294-300, 1993.

Garrat, J. R., Surface influence upon profiles in the atmospheric near-surface layer, Qt. J. R. Meteorol. Soc., 106, 803-819, 1980.

Garrat, J. R., and B. B. Hicks, Momentum heat and water vapour transfer to and from natural and artificial surfaces, Qt. J. R. Meteorol. Soc., 99, 680-687, 1973.

Gillette, D. A., Fine particulate emissions due to wind erosion, Trans. ASAE, 20, 890-897, 1977.

Gillette, D. A., I. H. Blifford, and D. W. Fryrear, The influence of wind velocity on size distribution of aerosols generated by the wind erosion of soils, J. Geophys. Res., 79, 4068-4075, 1974.

Gobierno de Aragon, Anuario estadistico agrario de Aragon 1993, Ed., Departamento de Agricultura, Ganaderia y Montes, Servicio de Estudios y Programas, Zaragoza, 99 pp, 1994.

Gomes, L., J. L. Arrue, G. Sterk, W. Holländer, and J. P. Frangi, Wind erosion and loss of soil nutrients in semiarid Spain (WELSONS). Abstracts of the International Conference on Mediterranean Desertification: Research Results and Policy Implications, European Commission, Environment and Climate programme, Crete, Greece 29 Oct.-1 Nov. 96. Report EUR 17782 EN, 1997.

Goutorbe, J. P., and co-authors, HAPEX-SAHEL: a large-scale study of land-atmosphere interactions in the semi-arid tropics, Ann. Geophysicae, 12, 53-64, 1994.

Hicks, B. B., Wind profile relationships from the "Wangara" experiments, Qt. J. R. Meteorol. Soc., 102, 535-551, 1976.

Högström, U. L. F., Nondimensionnal wind and temperature profiles in the atmospheric surface layer: a reevaluation, Bound.Layer Meteorol., 42, 55-78, 1988.

Högström, U. L. F., Review of some basic characteristics of the atmospheric surface layer, Bound.-Layer Meteorol., 78, 215246, 1996.

Holtslag, A. A. M., Estimates of diabatic wind speed profiles from near-surface weather observations, Bound.-Layer Meteorol., 29, 225-250, 1984.

Horton, R., P. J. Wierenga, and D. R. Nielsen, Evaluation of methods for determining the apparent thermal diffusivity of soil near the surface, Soil Sci. Soc. Am. J., 47, 25-32, 1983.

Idso, S. B., A set of equations for full spectrum and 8- to $14-\mu \mathrm{m}$ and 10.5 - to $12.5-\mu \mathrm{m}$ thermal radiation from cloudless skies, Water Resources Res., 17, 295-304, 1981.

Idso, S. B., R. J. Reginato, R. D. Jackson, B. A. Kimball, and F. S. Nakayama, The three stages of drying of a field soil, Soil Sci. Soc. Am. Proc., 38, 831-937, 1974.

Idso, S. B., R. D. Jackson, R. J. Reginato, B. A. Kimball, and F. S. Nakayama, The dependence of bare soil albedo on soil water content, J. Appl. Meteorol., 14, 109-113, 1975.

Jackson, R. D., R. J. Reginato, B. A. Kimball, and F. S. Nakayama, Diurnal soil water evaporation: comparison of measured and calculated soil water fluxes, Soil Sci. Soc. Am. Proc., 38, 861866, 1974.

Kimball, B. A., and R. D. Jackson, Soil heat flux determination: a null-aligment method, Agric. For. Meteorol., 15, 1-19, 1975. 
Kobayashi, T., W. He, and H. Nagai, Mechanisms of evaporation from soil with a dry surface, Hydrol. Process., 12, 2185-2191, 1998.

Kosmas, C., and co-authors, The effect of land use on runoff and soil erosion rates under Mediterranean conditions, Catena, 29, 45-59, 1997.

Larney, F. J., M. S. Bullock, S. M. McGinn, and D. W. Fryrear, Quantifying wind erosion on summer fallow in southern Alberta, J. Soil Water Cons., 50, 91-95, 1995.

Lee, J. A., B. L. Allen, R. E. Peterson, J. M. Gregory, and K. E. Moffett, Environmental controls on blowing dust direction at Lubbock, Texas, USA, Earth Surface Proc. Landforms, 19, 437449, 1994

Lopez, M. V., J. L. Arrue, and V. Sanchez-Giron, A comparison between seasonal changes in soil water storage and penetration resistance under conventional and conservation tillage systems in Aragon, Soil Tillage Res., 37, 251-271, 1996.

Lopez, M. V., M. Sabre, R. Gracia, J. L. Arrue, and L. Gomes, Tillage effects on soil surface conditions and dust emission by wind erosion in semiarid Aragon (NE Spain), Soil Tillage Res., 45, 91-105, 1998.

McAneney, K. J., and J. L. Arrue, A wheat-fallow rotation in northeastern Spain: water balance-yield considerations, Agronomie, 13, 481-490, 1993.

Marquardt, D. W., An algorithm for least-squares estimation of nonlinear parameters, J. Soc. Indust. Appl. Math., 11, 431-441, 1963.

Marticorena, B., and G. Bergametti, Modeling the atmospheric dust cycle: 1. Design of a soil-derived dust emission scheme, J. Geophys. Res., 100, 16415-16430, 1995.

Marticorena, B., G. Bergametti, B. Aumont, Y. Callot, C. N'Doume, and M. Legrand, Modeling the atmospheric dust cycle: 2. Simulation of Saharan dust sources, J. Geophys. Res., 102, 4387-4404, 1996.

Marticorena, B., G. Bergametti, D. A. Gillette, and J. Belnap, Factors controlling threshold friction velocity in semiarid and arid areas of the United States, J. Geophys. Res., 102, 23 277-23 287, 1997.

Mascart, P., J. Noilhan, and H. A. Giordani, Modified parametrization of flux-profile relationships in the surface layer using different roughness length values for heat and momentum, Bound.-Layer Meteorol., 72, 331-344, 1995.

Massman, W. J., Correcting errors associated with soil heat flux measurements and estimating soil thermal properties from soil temperature and heat flux plate data, Agric. For. Meteorol., 59, 249-266, 1992.

Massman, W. J., Periodic temperature variations in an inhomogeneous soil: a comparison of approximate and exact analytical expressions, Soil Sci., 155, 331-338, 1993.

Moller, J. T., Soil degradation in a north European region, in Proc. of Information Symp. in the EEC Programme on Climatology, Desertification in Europe, 15-18 April 1984, Mytilanae, Lesbos Island, Greece, Eds. Fantechi, R., and N. S. Margaris, D. Reidel, Dordrecht, The Netherland, 214-230, 1986.

Monin, A. S., and A. M. Obukhov, Basic laws of turbulence mixing in the atmosphere near the ground, Trudy Akad. Nauk. SSSR Geofiz. Inst., 24 (151), 163-187, 1954.

Montanes, L., M. Sanz, and L. Heras, Fertilidad de los suelos de secano de la provincia de Zaragoza, Diputation General de Aragon, Departemento de Agricultura, Ganaderia y Montes, Serie Estudios Agrarios, Zaragoza, 233 pp, 1991.

Nieuwstadt, F., The computation of the friction velocity $\mathrm{u}^{*}$ and the temperature scale $\mathrm{T}^{*}$ from temperature and wind velocity profiles by least-square methods, Bound-Layer Meteorol., 14, 235-246, 1978.

Obukhov, A. M., Turbulence in an atmosphere with a non-uniform temperature, Akad. Nauk. SSSR Inst. Theoret. Geofiz. Inst., 1, 95-115, 1946. (English translation in Bound.-Layer Meteorol., 2, 7-29).

Pan, H. L., and L. Mahrt, Interaction between soil hydrology and boundary-layer development, Bound.-Layer Meteorol., 38, 185202, 1986
Panofsky, H. A., A. K. Blackadar, and G. E. McVehil, The diabatic wind profile, Qt. J. R. Meteorol. Soc., 86, 390-398, 1960.

Paulson, C. A., The mathematical representation of wind speed and temperature profiles in the unstable atmospheric surface layer, J. Appl. Meteorol., 9, 857-861, 1970.

Passerat de Silans, A., B. A. Monteny, and J. P. Lhomme, The correction of soil heat flux measurements to derive an accurate surface energy balance by the Bowen ratio method, J. Hydrol., 188-189, 453-465, 1997.

Press, W. H., B. P. Flannery, S. A. Teukolsky, and W. T. Vetterling, Numerical recipes in FORTRAN: the art of scientific computing, Ed. Cambridge University Press, Cambridge, 818 pp, 1986.

Priestley, C. H. B., and R. J. Taylor, On the assessment of surface heat flux and evaporation using large-scale parameters, Mon. Weather Rev., 100, 81-92, 1972.

Prospero, J. M., and R. T. Nees, Impact of the North African drought and El Niño on mineral dust in the Barbados trade winds, Nature, 320, 735-738, 1986.

Quirantes, J., Aproximacion cualitativa y cuantitativa de los fenomenos de erosion eolica en el SE espanol, ICONA, Ministerio de Agricultura, Monografia 51, 84 pp, 1989.

Quiroga, A. R., D. E. Buschiazzo, and N. Peinemann, Management discriminant properties in semiarid soils, Soil Sci., 163, 591-597, 1998.

Rea, D. K., M. Leinen, and T. R. Janecek, Geologic approach to the long-term history of atmospheric circulation, Science, 227, $721-725,1985$.

Riehl, H., G. Greenhut, and B. R. Bean, Energy transfer in the tropical subcloud layer measured with a DC-6 aircraft during GATE, Tellus, 30, 524-536, 1978.

Richter, G., On the soil erosion problem in the temperate humid area of central Europe, Geojournal, 4, 279-287, 1980.

Sala, M., J. L. Rubio, and J. M. Garcia-Ruiz, Soil erosion studies in Spain, Ed., Geoforma Ediciones, Logrono, Spain, 228 pp, 1991.

Scanlon, B. R., Water and heat fluxes in desert soils: 1. Field studies, Water Resources Res., 30, 709-719, 1994.

Schneider, S. H., Encyclopedia of climate and weather, Oxford University Press, Oxford, UK, 929 pp, 1996.

Scott, W. D., Measuring the erosivity of the wind, Catena, 24, 163-175, 1995.

Sellers, P. J., F. G. Hall, G. Asrar, D. E. Strebel, and R. E. Murphy, The first ISLSCP field experiment (FIFE), Bull. Am. Meteorol. Soc., 69, 22-27, 1988.

Sellers, P. J., and co-authors, The boreal ecosystem-atmosphere study (BOREAS): an overview and early results from the 1994 field year, Bull. Am. Meteorol. Soc., 76, 1549-1577, 1995.

Sharratt, B. S., G. S. Campbell, and D. N. Glenn, Soil heat flux estimation based on the finite difference form of the transient heat flow equation, Agric. For. Meteorol., 61, 95-111, 1992.

Skidmore, E. L., Assessing wind erosion forces: directions and relative magnitudes, Soil Sci. Soc. Am. J. Proc., 29, 587-590, 1965.

Stebelski, I., Agricultural development and soil degradation in the Soviet Union: policies, patterns and trends, in Environmental problems in the Soviet Union and eastern Europe, Ed. Singleton, F, Lynne Rienner, London, 71-96, 1985.

Verhoef, A., B. J. van den Hurk, A. F. Jacobs, and B. G. Heusinkveld, Thermal soil properties for vineyard (EFEDA-I) and savanna (HAPEX-Sahel) sites, Agric. For. Meteorol., 78, $1-18,1996$.

Wood, N., and P. Mason, The influence of static stability on the effective roughness lengths for momentum and heat transfer, Qt. J. R. Meteorol. Soc., 117, 1025-1056, 1991.

Webb, E. K., Profile relationships: the log-linear range, and extension to strong stability, Qt. J. R. Meteorol. Soc., 96, 67-90, 1970.

Xu, Q., and C. J. Qiu, A variational method for computing surface heat fluxes from ARM surface energy and radiation balance systems, J. Appl. Meteorol., 36, 3-11, 1997.

Zobeck, T. M., Soil properties affecting wind erosion, J. Soil Water Cons., 46, 112-118, 1991. 